\title{
Aspectos históricos del temperamento de los instrumentos de teclado en España a finales del siglo XVII: de los proyectos toledanos a las realizaciones mediterráneas
}

\author{
Historical Aspects of the Temperament of Keyboard \\ Instruments in Spain at the end of the \\ Seventeenth Century: from the Toledan Projects to the \\ Mediterranean Achievements
}

Este artículo supone, en primer lugar, una síntesis de décadas de investigación sobre organería en España. Por otro lado, abre paso a un tema poco explorado de finales del siglo XVII y principios del XVIII: el temperamento de los instrumentos de tecla. El reciente descubrimiento del contrato de una hechura para la catedral de Toledo fechado en 1696 por parte de Liborna Echevarría, ofrece una nueva visión acerca de la construcción de su tiempo. Este contrato se pone en relación con el de Domingo Mendoza de 1695 para la construcción de un instrumento en esta misma catedral, lo que nos permitirá una reflexión comparativa de los proyectos y descubrir así distintas realidades musicales, y no solamente mecánicas, que separan a dos adalides de la organería española en su apogeo. Asimismo, una nueva lectura de los textos de la segunda mitad del siglo XVII nos aproxima a una doble orientación del temperamento del teclado. Por una lado, el que tiende al temperamento igual, protonal, de la tonalidad clásica, propio de Liborna Echevarría y Domingo Aguirre, que dominaría el frente occidental de la península. Por otro, el temperamento pretonal, con fuentes renacentistas, funciones prácticas y de precoz desaparición en el XVIII, que ganaría unas zonas surorientales con adelantos o resurgimientos en el centro valenciano. Este nacería de la actuación de Juan de Andueza seguido por su discípulo Domingo Mendoza. Ambas orientaciones tienen un mismo modelo: José de Echevarría.

Palabras clave: organería, península ibérica, Toledo, Murcia, Valencia, finales del siglo XVII, temperamento pretonal, temperamento protonal.

This article is, primarily, a synthesis of decades of research into organ building in Spain. But it also deals with a topic rarely considered: the temperament of keyboard instruments at the end of the seventeenth and early eighteenth centuries in Spain. The recent discovery of a 1696 contract to build an organ at the Toledo Cathedral, signed by Liborna Echevarría, provides a new perspective on the way organs were built at the time. Moreover, this contract can be compared with the one signed by Domingo Mendoza in 1695 for the construction of an instrument in this very cathedral, which allows us to compare and study the differences between the two projects. Indeed, these differences are 
not only mechanical but represent the two main standard bearers of the art of Spanish organ building at its height. A new interpretation of both documents will also give us a better understanding of the two main approaches to keyboard temperament: the one tending towards equal temperament, with a "tonal" orientation, from classical harmony (characteristic of Liborna Echevarría and Domingo Aguirre), which dominated the Western part of the Peninsula; and the one tending towards a "pretonal" or "modal" temperament, whose origins are to be found in the Renaissance period and which disappeared during the eighteenth century. The latter was widely used in South-Eastern Spain, developed and revived around the city of Valencia and inspired by Juan de Andueza and his pupil Domingo Mendoza. Both approaches used friar José de Echevarría as their model.

Keywords: organ building, Iberian Peninsula, late-seventeenth- and early-eighteenth-century instrumental music, Pre-tonal temperament, tonal temperament.

En trabajos anteriores he aludido repetidamente a las dos figuras de la organería que, a finales del siglo XVII, llegan a Madrid para imponer en la ciudad, y desde allí a otras localidades, nuevas y definitivas dimensiones del órgano ibérico. Uno es Domingo Mendoza, navarro nacido en Lerín, y el otro Pedro Liborna Echevarría, vasco, oriundo de Eibar.

Mendoza llega a Madrid de la mano de su maestro Juan de Andueza', igualmente nacido en Lerín. Andueza es discípulo directo del franciscano José de Echevarría, mientras que su discípulo Mendoza, aunque observador directo de las obras del maestro, pertenece a una segunda generación, que corresponde a los años ochenta del siglo XVII. Andueza está en la capital en 1675, pero no se conoce aún la fecha del asentamiento de Mendoza. Lo que se sabe es que en 1686 figura como testigo de la obligación de Juan de Andueza para la construcción de un órgano para Almonacid de Zorita (Guadalajara), que en 1687 procede a la tasación del taller del organero Ventura de Chavarría y que ese mismo año, ya muerto su maestro, cobra de su viuda, Sebastiana de Ávila (hija del organero Gabriel de Ávila) lo que se le debe de su salario de oficial (o aprendiz) hasta el 30 de noviembre de 1686, que asciende a 720 reales. En 1691 es organero del real convento madrileño de la Encarnación y en 1692 empieza la hechura de los órganos de la catedral de Cuenca.

El segundo, Pedro Liborna Echevarría, es discípulo directo de la primera generación del mismo José de Echevarría, quien realiza su última obra en la catedral de Palencia, donde muere el 10 de mayo de 1691. Pedro Liborna Echevarría ayuda a su maestro en la construcción de dicho órgano durante dos períodos (del 15-III-1689 al 29-IV-1689 y del 1-II-1690 al 29-VII-1690), entre los cuales había afinado el órgano de la iglesia San Luis de los Franceses (Madrid). En 1691 solicita la plaza de organero del rey, pero no consigue su primer contrato conocido en la capital hasta 1696.

\footnotetext{
${ }^{1}$ Sobre los organeros citados en este artículo véase el diccionario de L. Jambou: Les facteurs d'orgues en Espagne, 1400-1850, ed. Delatour-France (en prensa).
} 
También he aludido en anteriores trabajos a las diferencias que hubo entre ambos discípulos, directo uno e indirecto el otro, del maestro franciscano. Estas se manifestaron en soluciones técnicas distintas (empleo de la madera o del hierro en los movimientos de la caja de ecos) en sus realizaciones $^{2} \mathrm{o}$ en orientaciones organeras más profundas ${ }^{3}$, que nunca se concretan en sus escritos, pero a partir de los cuales se pueden deducir.También he señalado que Domingo Mendoza citaba al maestro (que en este caso era Andueza e, indirectamente, Echevarría) mientras que Liborna Echevarría nunca aludió a José de Echevarría, maestro forjador del órgano español. El presente artículo pretende, siempre con una lectura más histórica que acústica, dar solución, o sugerirla por lo menos, a las diferencias que separan a los dos organeros y que provienen de las realizaciones de un mismo maestro. Como veremos, estas marcan una tercera orientación del órgano español en los años de su apogeo.

\section{Proceso histórico de la hechura del órgano del Evangelio en la catedral de Toledo}

El Cabildo de la catedral de Toledo se preocupó tempranamente por la construcción de instrumentos nuevos en el recinto de su templo. En septiembre de 1678 el recién nombrado racionero organista, José Solana, remite un informe al cabildo; este decide, el 26 de octubre, remitir al cardenal arzobispo un acuerdo por el cual desea "se hagan órganos competentes con todo aquel lleno y primor que requiere la grandeza de esta S. ${ }^{\text {ta }}$ Iglesia" ". Este acto capitular no tiene efecto hasta los años 1695-1704. Como ya he mencionado en otros trabajos, "esta aparente tardanza no es signo de negligencia por parte del cabildo sino preocupación por construir un órgano digno de la catedral" ${ }^{1}$. Los motivos de este largo e infrecuente período ${ }^{6}$, más de

\footnotetext{
2 L. Jambou: Evolución del órgano español. Siglos XVI-XVIII, Oviedo, Universidad de Oviedo, 1988, vol. I, pp. 182, 291, 308.

${ }^{3}$ L. Jambou: "El órgano en la península ibérica entre los siglos XVI y XVIII: Historia y estética", Revista de Musicología, II, 1, 1979, pp. 19-46; apunto ya en p. 42 una sucesión inmediatamente de uno y otro; preciso ya las divergencias en L. Jambou: Evolución..., por ejemplo sobre el empleo de un flautadillo de acompañamiento en los ecos, vol. I, p. 291; entre otros trabajos lo abordo más concretamente en L. Jambou: "Los órganos", La catedral primada de Toledo. Dieciocho siglos de historia, Toledo, Promecal, 2010, pp. 353-361; id.: "Les deux orientations d'une école unique de l'orgue espagnol à son apogée: l'exemple de Tolède à la fin du XVII ${ }^{2}$ è siècle", Orgues Nouvelles, n. ${ }^{\circ}$ 8, 2010, CDrom. En todos ellos se desconocía el contrato obligando a Pedro Liborna y Echevarría a construir el órgano catedralicio. El conocimiento de este (Apéndice I) permite enfocar de modo más lúcido sus divergencias, si las hay, y los motivos posibles de la preferencia del arzobispo (ver abajo) y del cabildo por su proyecto.

${ }^{4}$ L. Jambou: Evolución..., vol. I, pp. 167-168 (esquema resumido); id.: "José Solana (1643-1712). Trayectoria de un organista compositor", Revista de Musicología, IV, 1, 1981, pp. 93 y ss.; pp. 108-109 (documentos).

${ }^{5}$ L. Jambou: "José Solana (1643-1712)...", p. 93.

${ }^{6}$ Ibid., pp. 93-99.
} 
veinte años, se han analizado ya, y pueden ser tanto el marco de la crisis económica de orden nacional como problemas en el ámbito local, es decir, la de la misma obra o fábrica del cabildo toledano. Por una parte, la puesta a punto del nuevo órgano ibérico, que llega a su apogeo durante estas décadas, puede haber originado esta duración o lentitud. Por otra parte, Miguel Puche, el organero titular, muere en 1688, y no habiendo "persona de ygual satisfacción e ynteligencia en este ministerio que cuide de sus reparos" ", los órganos catedralicios quedan desamparados durante años pese a que se realizan reparaciones puntuales ${ }^{8}$.

De Mendoza se conocía ya desde hace tiempo el contrato con el cabildo $y$, sin que se conociesen las causas, su cancelación ${ }^{9}$; el contrato con Pedro Liborna Echevarría nos ha llegado a través de una copia conservada en el archivo catedralico de Toledo ${ }^{10}$. Con estos documentos es posible trazar el proceso de construcción y ver las características esenciales de dicho instrumento, de manera que para la realización del órgano en que triunfa el modelo barroco del órgano español tenemos ya todos los documentos del proceso de construcción y de reconocimiento del instrumento que puedan servir para un amplio análisis crítico ${ }^{11}$. No seguiré aquí el análisis de aquel conjunto arquitéctonico y sonoro que, a partir de 1755, dio paso a la realización de una unión visual y sonora, casi simétrica también, de los dos órganos de coro; la reflexión se limitará al proyecto ideado por Mendoza así como al instrumento realizado en la catedral primada por Liborna Echevarría y los dos reconocimientos hechos a distancia de cinco años por el maestro Sebastián Durón. Podremos así comparar dos proyectos para el mismo edificio catedralicio de dos jóvenes organeros formados en la misma

\footnotetext{
${ }^{7}$ Ibid., p. 108, documento XVII.

${ }^{8}$ Aunque está activo en 1688 como titular del monasterio de Santo Domingo el Real, el hijo de Miguel Puche, Joaquín, no será titular de los órganos catedralicios. Procediendo de Palencia, Antonio Chavarría interviene en los órganos de la catedral toledana en 1691. A este maestro se le paga un salario de 68.000 maravedíes hasta el 1 de enero de 1695 en que desaparece el título de "afinador de órganos". Ver Catedral de Toledo, Actas Capitulares [ACTo], Obra y fábrica, año 1694 (frutos de 1693, f. 79v) que no volverá a aparecer hasta Martínez Colmenero en 1704.

${ }^{9}$ L. Jambou: Evolución..., vol. II, n. ${ }^{\circ} 241$ (p. 110, del 6-VIII-1695 con poder otorgado en Toledo el 28-VII-1695), n. ${ }^{\circ} 248$ (p. 115, del 1-VIII-1696).

${ }^{10}$ ACTo, Secretaría capitular, Caja "Órgano"; ver Apéndice, documento I.

${ }^{11}$ Además de los citados en las notas anteriores, véase en L. Jambou: Evolución..., II, los n. os 250 (p. 116 del 29-XI-1696 contrato de la caja con José Machín, maestro de arquitectura, según diseño de Teodoro de Ardemans, maestro mayor de obra de la catedral); n. ${ }^{\circ} 253$ (p. 118 del 1-IX-1698, contrato del dorado de la caja por Juan Alonso de Paz, maestro de dorado); nº 256 (p. 119, del 10-IX-1699 que recibe la primera declaración del órgano por Sebastián Durón); n. 274 (del 19-V-1704, que recibe la segunda declaración del órgano por Sebastián Durón). Sobre los dibujos preparatorios a la hechura de la caja, véase A. Fernández Collado, Alfredo Rodríguez González, Isidoro Castañeda Tordera: Los diseños de la catedral de Toledo. Catálogo de diseños arquitectónicos, artísticos, topográficos y textiles, Toledo, Instituto Teológico San Ildefonso, Colección Primatialis Ecclesias Toletanae Memoria, 5, 2009, pp. 173-174. Sobre los dibujos de cajas de 1696 y contratos ver también el estudio de Juan Nicolau Castro: "Obras del siglo XVIII en la catedral de Toledo", Anales Toledanos, XIX, 1984, pp. 203-240.
} 
escuela y comprobar si en Toledo, punto de encuentro de dos orientaciones, coinciden o se diferencian las técnicas y estéticas en la hechura de un órgano en el primer momento del apogeo del órgano ibérico.

Se duda de que el cabildo toledano, entre 1678 y 1695, haya encontrado "personas inteligentes e idóneas" y haya puesto a prueba su ambición renovadora. Pero a finales de 1695 o a principios de 1696 Mendoza está en Toledo reparando los órganos; el 18 de abril de este año cobra 50936 maravedís "por el trabajo de haver venido a afinar los órganos de esta S.I." ${ }^{12}$ ¿Puesta a prueba de un organero poco o nada conocido, como suele hacerse en Toledo, anticipando así un contrato de afinador? No se sabe, pero la prueba es suficiente para otra mayor, ya que se le contrata para una hechura nueva. En efecto, el mismo año, el 6 de agosto de 1695, el organero otorga en Madrid una escritura por la cual se obliga a "la hechura de un órgano que se ha de hazer para la santa iglesia de Toledo" por un valor de 60000 reales y entrega en un plazo de un año ${ }^{13}$.

Pero esta obligación va seguida, curiosamente y sin explicaciones, de su cancelación por otra escritura otorgada también en Madrid el 1 de agosto de $1696^{14}$. Esta puntualiza solamente que Mendoza ha de devolver la mitad de la cantidad recibida de la Obra y Fábrica: 6000 reales de los 12000 entregados. Esta cantidad se queda corta en relación con el importe total, 60000 reales, lo que hace suponer que no podía cumplir la entrega en el plazo exigido para estas mismas fechas. Este motivo, sin embargo, no deja de ser ilusorio, ya que estos retrasos, que no son tales porque la escritura de renuncia coincide con el año cumplido de la obligación, se dan frecuentemente en el campo de la organería. Es verdad que, buscando motivos de la anulación, tampoco se pueden descartar las noticias que irían llegando de Cuenca sobre el acabado de los órganos de la catedral por el maestro lerinés. Rumores sin duda, pero rumores reforzados por la reanudación de la obra conquense por el maestro valenciano Roque Blasco seguido, después del fallecimiento de este, por su sobrino José Bertrán.

12 Bibliotea Nacional de España (BNE), Papeles de Barbieri, Mss. 14036/82. Pese a anunciar el apellido y título: "Mendoza, Domingo (Organero, 1695)", tal libramiento no aparece en E. Casares: Francisco Asenjo Barbieri. Biografías y documentos sobre música y músicos españoles (Legado Barbieri), vol. 1, Madrid, Fundación Banco Exterior, 1986, p. 329. La carta del cabildo de Ávila (26-I-1702) que contesta a otra el cabildo de Sigüenza (14-I-1702) no figura en la BNE, Papeles de Barbieri, Mss. 14036/81. Es tema que abordamos ya en Evolución..., I, p. 308, que volvemos a tratar aquí de modo más preciso, como lo hice en "Les deux orientations d'une école unique de l'orgue espagnol à son apogée: l'exemple de Tolède à la fin du XVIIème siècle", Orgues nouvelles, Printemps, 2010, CD. Pese al carácter mesurado de esta clase de correspondencia, es una lástima que no se conozca ya que entre Mendoza y Liborna Echevarría parece haber divergencias no solo comerciales sino también técnicas y musicales.

${ }^{13}$ L. Jambou: Evolución..., II, n 241.

${ }^{14}$ Ibid., $\mathrm{n}^{\circ} 248$. 
Pero en Toledo las fechas y obligaciones se cruzan y extraña que, en el entramado de compromisos sobre el órgano, esta cancelación sea posterior a un doble compromiso en que Liborna Echevarría aparece como principal o como firmante. Uno, con fecha del 8 de junio de 1696, obliga a Pedro Liborna Echevarría a construir un órgano para la misma iglesia catedral por la cantidad de 56000 reales. En la segunda escritura José Machín, maestro de arquitectura, firma el 19 del mismo mes y año la obligación de la hechura de la caja de este órgano, según una planta dibujada por Teodoro Ardemáns ${ }^{15}$, firmada por este y por el maestro organero Pedro Liborna Echevarría. Mendoza esperará un mes largo, el 1 de agosto de 1696, antes de ser apartado de la misma obra. El dorado de la caja se encargaría a Juan Alonso de Paz, "maestro de dorado", el 1 de septiembre de 169816. Domingo Mendoza ha quedado así descartado de la catedral toledana y es el joven maestro eibarrés quien lleva la hechura de la obra en dos etapas.

El 10 de septiembre de 1699, a los tres años, el primer organista de la Capilla Real de Madrid y maestro de capilla de la misma, Sebastián Durón, prueba el instrumento repetidamente, en varios días y ocasiones, junto con los tres organistas de la catedral (José Solana, racionero titular, Pedro Gaude y Francisco de Cárdenas), su maestro de capilla (Pedro de Ardanaz) y otros músicos. Reconoce que el instrumento está acabado según las condiciones del contrato y que, además de ellas, ha hecho de más: "un flautado tapado en lugar de otro, un segundo clarín de fachada, un churumbelado, una recímbala, ocho contras bajos de trompeta real y que en la cadereta hizo nasartes en $12^{\text {na }}, 15^{\text {na }}$ y $19^{\text {na" }}$. Así como en la parte de atrás (en la nave de San Pedro, o septentrional) dos castillos con una tubería "muda". La escritura, que firma solo, no declara nada en cuanto al importe que el organero debería haber cobrado por estos aumentos ni por el "guante" que se estilaba dar por la obra hecha.

En 1704 Liborna Echevarría había realizado ya el órgano de la Epístola de la catedral de Segovia y estaba terminando los instrumentos del monasterio de El Escorial. Pero el 10 de mayo de ese mismo año Liborna Echevarría vuelve a revisar el instrumento toledano después de haberlo "apeado y limpiado"y dejado en toda perfección, según Sebastián Durón ${ }^{17}$. Firma solo, como lo hizo en 1699, la escritura en la cual aparecen como testigos Sebastián Montero, Alonso Carbonero y el maestro de capilla Pedro de Ardanaz, trabajo que tenía que haber hecho a los dos años de su finalización

\footnotetext{
15 Véanse los contratos de la caja y su dorado en ibid., n. ${ }^{\circ} 250$. Sobre esta caja y la de 1756 , véase J. Nicolau Castro: "Obras del siglo XVII en la catedral de Toledo", Anales de Toledo, XIX, 1984, pp. 203240. Este artículo reproduce el dibujo de la caja de 1696 así como la traza del reverso que hizo Germán López en 1757 para el órgano de la Epístola.

${ }^{16}$ L. Jambou: Evolución..., II, n. ${ }^{\circ} 253$.
} 
(es decir en 1701). Esta vez, sin que se precise el importe, se le ha de satisfacer las "demasías" que ha hecho según la declaración anterior de 1699.

Entre la primera escritura, con Mendoza, y esta declaración, han transcurrido nueve años de un proceso que empezó en 1677-78. Son muchos años, pero a principios del siglo XVIII el coro de la catedral de Toledo ostenta una muestra maravillosa del auge del arte barroco con una caja ${ }^{18}$ firmada por un maestro arquitecto, Teodoro Ardemáns, y un órgano ibérico de uno de los discípulos directos del fundador, Pedro Liborna Echevarría. El cabildo toledano y su arzobispo, el cardenal Portocarrero, que sigue el proceso de la hechura, gozan de un maravilloso instrumento y una caja ideada al mismo tiempo, él mismo testigo (que no tendrá su réplica hasta los años 1755-56) de una plena arquitectura barroca. Esta larga emergencia y pleno florecimiento no puede ocultar las divergencias entre los dos maestros que, no declaradas ni simultáneas sino implícitas y sucesivas, se empalman y acoplan $^{19}$. Mendoza y Liborna Echevarría, se han cruzado en Toledo y podemos ahora considerar sus convergencias o divergencias a través de sus planes y proyectos. Los años que separan la primera escritura de la realización final constituyen un período largo e infrecuente, como se mencionó antes, pero vale la pena que, antes de considerar el objeto -los dos proyectos- del conflicto entre Mendoza y Liborna Echevarría, saquemos a relucir a la persona que sin duda anima los encuentros entre organeros, músicos y teóricos que no aparecen en los textos y que ha podido ser influyente en este proceso: su mecenas, el cardenal de la sede de Toledo, Portocarrero.

\footnotetext{
${ }^{17}$ L. Jambou: Evolución..., n. ${ }^{\circ} 274$.

${ }^{18}$ El valioso libro de S. R. Parro: Toledo en la mano, Toledo, 1857, contiene, en su vol. II, la descripción, quizá la primera (también figura otra algo posterior en A. Pérez: "Órganos en la catedral de Toledo", Revista y Gaceta Musical, 31, 1-VIII-1867, p. 166-67 y 31, 11-VIII-1867, pp. 172-173), de los tres órganos tal como se construyen a partir de esta mitad de siglo XVIII: pp. 200-201, el órgano del coro del Arzobispo (el de la Epístola); pp. 202-207, el órgano nuevo (del Evangelio, el de Jose Verdalonga), "uno de los mejores que en su clase se conocen dentro y fuera de España"; pp. 310-312, el órgano del Emperador. Los tres, que considera "únicamente como instrumentos músicos"( p. 200), están descritos bajo su aspecto visual, la caja, como en la disposición de sus registros y mecanismos, llegando a precisar, sobre todo para el de la Epístola el papel de cada teclado o, para el del Evangelio, los mecanismos de acoplamiento. Sin embargo, se ha de tener en cuenta que, escribiendo en los años 1850 y pese a tener a mano para algunos de los instrumentos los contratos o escrituras originales, se remite sin duda también a lo que ve directamente o lo que le describen los mismos actores de mediados de siglo, organistas u organeros. Así, del órgano de la Epístola dice que tiene tres teclados de 51 teclas cada uno, cuando el contrato con Pedro de Liborna Echevarría escribe que tiene dos de 51 teclas cada uno. Es de suponer que la ampliación a tres teclados se hizo a partir del momento en que José Verdalonga termina las obras y que el cabildo vuelve a pensar en hacer otra caja simétrica a la nueva neoclásica a finales del XVIII o principios del XIX, véase ibid., p. 207, nota 1. Del año siguiente, 1858, es la descripción del órgano del Evangelio del profesor del Conservatorio de Madrid, R. Jimeno: Método completo teórico y práctico de órgano, Madrid, 1858, pp. 82-84.

19 Sobre la vida organística toledana a finales del XVII y principios del XVIII véase L. Jambou: "José Solana (1643-1712)...". Sobre la vida musical de la catedral durante la primera mitad del siglo XVIII véase Carlos Martínez Gil: La capilla de música de la Catedral de Toledo (1700-1764). Evolución de un concepto sonoro, Toledo, Junta de Castilla y León, 2003.
} 


\section{El papel del cardenal arzobispo de Toledo, Luis Fernández de Portocarrero, y las dos orientaciones del órgano español}

El motor de la nueva hechura y su mecenas, como en el caso de otros nobles y prelados de este final de siglo, es Luis Fernández de Portocarrero (1635-1709), elegido arzobispo de Toledo en 1677. Un reciente estudio permite conocer su estancia, entre 1671 y 1679, en Italia ${ }^{20}$. En estas tierras reside sobre todo en Roma, pero también en Palermo, Nápoles yVenecia, entre otras ciudades. Así entra en contacto con la música y compositores como Arcangelo Corelli, Filippo Coppola y Alessandro Scarlatti, que pudo conocer en el ambiente de la familia de los Orsini, de Cristina de Suecia o del cardenal Carlo Barberini. Si aún no se conoce el grado de preparación musical que pudo tener, por lo menos se puede medir su conocimiento musical a través del conexto de sus estancias por tierras italianas. De este modo, su vuelta a la Península se entiende mejor y se puede dar mayor significado a la cena-concierto en la que participó Madame d'Aulnoy en el palacio-arzobispal toledano, en 1679, durante la cual se escuchó música italiana gracias a músicos que "su Eminencia había traído" de Roma²1. Es de notar que por las mismas fechas el cabildo catedralicio pide a su organista, José Solana, que hiciera un informe sobre el estado de los órganos, como se anotó más arriba, y que el cabildo comunicara esta solicitud el 20 de octubre 1678 al cardenal arzobispo ${ }^{22}$. Aún no se pueden medir los encuentros o conversaciones que pudo haber tenido el cardenal, en Madrid principalmente, o en Toledo, en la elaboración del proyecto durante el primer tramo de este largo periodo. Pero se puede entender y concretar mejor, en fechas posteriores, su interés en la realización final a partir de los gastos ordenados por el mismo cardenal. En primer lugar van los relativos a los instrumentos: por orden del cardenal se le libran 50936 maravedís el 18 de abril de 1695 por afinar los órganos, el 22 de marzo 1696408000 maravedís “por quenta de el órgano que se esta haçiendo en Madrid”, el 1-VIII-1696 10.160 maravedís que importaron "los materiales que se trajeron [desde Madrid] por el carro p[ar]a el organo que avia de hazer Domingo Mendoza"23. De modo

\footnotetext{
20 José María Domínguez Rodríguez: "Música, ceniza y nada: semblanza melómana del cardenal Portocarrero (1635-1709)", Creer y entender. Homenaje a Ramón Gonzálvez Ruiz, Real Academia de Bellas Artes y Ciencias Históricas de Toledo, Toledo, 2014, vol. 2, pp. 891-902.

${ }^{21}$ Ibid., p. 901. Esta anécdota deja suponer, como afirman algunos, que la música italiana se introdujo en Toledo desde el último tercio de este siglo. Las actas capitulares o los libros de fábrica de la catedral, principal motor musical en la ciudad, no dejan traslucir hasta ahora esta renovación. Pero el repertorio cantado o tocado puede matizar esta afirmación, ahondando sobre todo en las orientaciones estilísticas de Diego Fernández de Huete.

${ }^{22}$ L. Jambou: "José Solana (1643-1712)...", pp. 108-109.

23 ACTo, Obra y Fábrica 1695, Frutos del año 1694. Año de 1695. ACTo, Obra y Fábrica 1695, Frutos del año 1694. Año de 1695, f. 116v; Obra y Fábrica 1696, Frutos del año 1695. Gasto en el año 1696, f. 113.
} 
paralelo, en segundo lugar, se les paga a dos peritos, organista y organero, para el examen del trabajo y de las condiciones de dicho órgano nuevo. El 12 de marzo de 1695 se libran al receptor general de la obra Joseph de Atocha, "sesenta mill seiscientos y veinte y cuatro mrs por los mismos que en treinta doblones de a dos escudos que [...] ha dado por mando darle el Car[dena]l mi s[señ]or de orden de el señor obrero mayor a el Padre Fr. Martin Garcia Religioso de la Orden de la S[anti]ssima Trinidad y organista mayor de la s[an]ta ygl[e]sia mayor de Cuenca que ha venido desde dicha ciudad llamado a reconocer y declarar los reparos que necesitan los organos desta s[an]ta ygl[esi]a q[ue] lo executo assi". Este mismo día y año, 12 de marzo de 1695, se libraron al mismo Joseph de Atocha "seiszientos rs de vellon que valen 20400 mrs por los mismos que entrego a fr. Domingo Aguirre. Maestro de azer organos que vino desde la ziudad de Plasencia. Por mandado del s[eñ] or Car [denal] mi s[eñ]or a ber y rreconozer las condiciones del organo que se esta haçiendo en Madrid, para esta santa ygl[esi]a y a hazer declaraçion sobre lo que sintiere"24.

Notemos que en ambos casos estos peritos vienen llamados por el cardenal Portocarrero. Desde hace tiempo se conoce a fray Martín García [Olagüe], organista en su convento madrileño antes de llegar a serlo en la catedral de Cuenca. En ambos lugares se construyen órganos, el primero en Madrid por Juan de Andueza y los segundos (son dos) en Cuenca por su alumno Domingo Mendoza: se puede suponer así, que el organista es eI portavoz de esta orientación de la organería. Domingo Aguirre, que este año está en Plasencia trabajando en el órgano catedralicio, presenta un caso paralelo, aunque algo más oscuro por falta de documentos. Lo cierto es que culmina en 1691 el órgano de la catedral de Palencia, la última obra ideada por su maestro José Echevarría. Este órgano presenta un teclado enarmónico, según declaraciones de Antonio Soler. No dudo aquí, aunque sea mera sugerencia, en colocarle de parte de este organero. Estos expertos, organistas y organero, representan en Toledo las dos orientaciones del temperamento del teclado a finales del siglo XVII: una orientación pretonal, mesotónica -la del grupo José Echevarría-Andueza-Mendoza- y una orientación "de temperamento protonal o proigual"-la del grupo Liborna Echevarría-Aguirre-. Como se indicó arriba, todo indica que quien tiene la última palabra en la elección final es el mismo cardenal Portocarrero. Las fechas de los documentos notariales son aclaratorias: el 12 de diciembre de 1694 Domingo Mendoza propone las condiciones del órgano de la catedral y el 6 de agosto de 1695 firma la obligación de hechura de su órgano. Pedro Liborna Echevarría firma en Madrid la escritura de obligación de su

\footnotetext{
${ }^{24}$ ACTo, Obra y Fábrica 1695, Frutos del año 1694. Año de 1695, f.116r. Es de señalar que los gastos indicados se refieren solo al órgano de Mendoza.
} 
órgano el 8 de junio de 1696. La cancelación de la escritura de Domingo Mendoza se hizo el 1 de agosto de 1696, es decir, después de la obligación con Liborna Echevarría y un mes largo antes de la entrega acabada de su órgano estipulada por la escritura del 6 de agosto de 1695 (que dice para "Nuestra Señora de agosto del año que viene de 96"). El cardenal Portocarrero se inclina de forma brusca, por las fechas de los documentos -que no tienen en cuenta otros posibles documentos o discusiones con especialistas ni anterior experiencia-, por la orientación protonal de Liborna Echevarría.

\section{Los proyectos toledanos de 1695 y 1696 de Mendoza y Liborna} Echevarría: una doble orientación

Las disposiciones que siguen son las que figuran en la escritura de obligación de Mendoza ${ }^{25}$, en la de Liborna Echevarría (que se publica en el Documento I del apéndice) y en el reconocimiento de este órgano por Sebastian Durón en $1699^{26}$.

El magisterio en la eclosión final del órgano español -entre 1660 y 1690- no ofrece lugar a dudas: pese a la multiplicidad de organeros, es único en torno a José de Echevarría. Los dos contratos de 1695 y de 1696 tienen esta fuente primera y directa; su esquema arriba dibujado no permite señalar dos orientaciones organeras tan profundas como para diferenciar dos escuelas distintas: la fuente de ambas es la misma y se cifra en el tronco común del teclado partido, heredado del siglo XVI, con sus dos ramas de la segunda mitad del siglo XVII: el sistema de ecos con su caja expresiva o caja de ecos y la trompetería horizontal. Sin embargo, entre ambos se notan divergencias, tanto en estos contratos como en otros, que conviene aclarar.

Notaremos en primer lugar elementos externos que son proclamas afirmativas, explícitas o implícitas, de uno y otro. Mendoza, en este contrato como en otros posteriores, se relaciona o afirma con una red de referencias que son sus maestros o una tradición confirmada.Aquí en Toledo se refiere al órgano del Buen Suceso (de Madrid) que se puede suponer del fraile franciscano, de Ventura Chavarría o de su maestro directo Juan de Andueza ("mi maestro" dice, en 1700 , en relación con la "corneta magna" de 7 caños por punto en la catedral de Sigüenza), lo mismo que alude, en el órgano de ecos, a la corneta hecha por este en la Capilla Real de Madrid (en 1675). Asimimo acude al padre fundador del nuevo instrumento, José de Echevarría, cuando recomienda el clarón "acornetado como el que

\footnotetext{
${ }^{25}$ L. Jambou: Evolución..., II, n 241, pp. 110-111.

${ }^{26}$ Ibid., n. ${ }^{\circ} 256$, p. 119.
} 
DISPOSICIÓN DEL ÓRGANO DEL EVANGELIO IDEADO PARA LA CATEDRAL DE TOLEDO POR DOMINGO MENDOZA (escritura del 6-VIII-1695, cancelada el 1-VIII-1698)

\begin{tabular}{|c|c|c|}
\hline $\begin{array}{c}\text { MANO } \\
\text { IZQUIERDA }\end{array}$ & $\begin{array}{l}\text { MANO } \\
\text { DERECHA }\end{array}$ & OBSERVACIONES \\
\hline & & \\
\hline & & \\
\hline & & \\
\hline \multicolumn{2}{|c|}{ ÓRGANO GRANDE } & \multirow[b]{2}{*}{ Dentro del mismo órgano } \\
\hline $\begin{array}{lrr}\text { Flautado } & \text { de } & 26 \\
\text { palmos [de } & \text { madera } \\
\text { empapelados } & y \\
\text { encolados por dentro] }\end{array}$ & $\begin{array}{l}\text { Flautado de } 26 \\
\text { palmos lla media } \\
\text { mano alta: de } \\
\text { estaño] }\end{array}$ & \\
\hline Flautado de 13 & Flautado de 13 & $\begin{array}{l}\text { Ha de ser el mismo que tiene el } \\
\text { órgano que está donde se ha de } \\
\text { poner el nuevo }\end{array}$ \\
\hline $\begin{array}{l}\text { Flautado } \\
\text { tapado }\end{array}$ & $\begin{array}{l}\text { Flautado violón } \\
\text { tapado }\end{array}$ & \\
\hline $\begin{array}{l}\text { Otro registro de } \\
\text { tapadillo }\end{array}$ & Tapadillo & $\begin{array}{l}\text { Ha de servir otro }[\ldots] \text { que tiene } \\
{[\ldots] \text { el órgano viejo }}\end{array}$ \\
\hline Octava abierta & Octava abierta & de 6 palmos \\
\hline Docena mayor & Docena mayor & \\
\hline Quincenas & Quincenas & $\begin{array}{l}\text { Duplicadas dede el segundo } \\
\text { cesolfaut }\left[\mathrm{Ut}^{2}{ }^{2} \mid 82 \text { caños }\right.\end{array}$ \\
\hline Decinovenas & Decinovenas & $\begin{array}{l}\text { Duplicadas desde el segundo } \\
\text { cesolfaut }\left[\mathrm{Ut}^{2}{ }^{2}: 82 \text { caños }\right.\end{array}$ \\
\hline $\begin{array}{l}\text { Nasarte mayor en } \\
12^{\text {sat }}\end{array}$ & $\begin{array}{l}\text { Nasarte mayor en } \\
12^{2 \mathrm{a}}\end{array}$ & \\
\hline Otro nasarte & Otro nasarte & \\
\hline $\begin{array}{l}\text { Lleno de } 4 \text { c.p.p. y su } \\
\text { primer punto entra } \\
\text { en } 22^{\text {ma }}\end{array}$ & Lleno de 4 c.p.p. & \\
\hline Címbala de 3 c.p.p. & $\begin{array}{l}\text { Címbala de } 3 \\
\text { c.p.p. }\end{array}$ & $\begin{array}{l}\text { Como la que está en el Buen } \\
\text { Suceso en Madrid }\end{array}$ \\
\hline Clarón de 4 c.p.p. & Clarón de 4 c.p.p. & $\begin{array}{l}\text { Acornetado }[\ldots] \text { como el que } \\
\text { hizo el Padre Echevarría en la } \\
\text { santa iglesia de Palencia }\end{array}$ \\
\hline & & \\
\hline & & \\
\hline Registros $\mathrm{C}$ & e lengua & \\
\hline Trompetas reales & Trompetas reales & De madera de peral \\
\hline $\begin{array}{l}\text { Otro de trompetas } \\
\text { reales }\end{array}$ & $\begin{array}{l}\text { Otro de trompetas } \\
\text { reales }\end{array}$ & De estaño \\
\hline & $\begin{array}{l}\text { Medio registro de } \\
\text { thenor de chirimía }\end{array}$ & $\begin{array}{l}\text { En unísonus con el flautado de } \\
26[\ldots] 24 \text { trompetas y han de } \\
\text { ser de madera de peral }\end{array}$ \\
\hline Bajoncillo & & $\begin{array}{l}\text { Octava arriba de la trompeta. } \\
\text { Lleva } 22 \text { trompetas. }\end{array}$ \\
\hline Voz humana & Voz humana & \\
\hline $\begin{array}{l}\text { Medio registro bajo } \\
\text { de trompeta de batalla }\end{array}$ & & $\begin{array}{l}\text { Ha de salir por entre los caños } \\
\text { de la fachada en forma de } \\
\text { artillería. } 21 \text { trompetas }\end{array}$ \\
\hline & $\begin{array}{l}\text { Medio registro de } \\
\text { Corneta magna de } \\
7 \text { c.p.p. }\end{array}$ & $\begin{array}{l}1^{\text {cr cr caño: Unisonus del flautado. }} \\
168 \text { caños }\end{array}$ \\
\hline & $\begin{array}{l}\text { Medio registro de } \\
\text { clarín }\end{array}$ & $\begin{array}{l}\text { Puesto en artillería. De bronce. } \\
24 \text { clarines. }\end{array}$ \\
\hline Dulzainas & Dulzainas & De bronce. Puesto en artillería. \\
\hline Flautado de 13 & Flautado de 13 & Ha de hablar en $5^{\mathrm{ta}}$ del de 13 \\
\hline Octava abierta & Octava abierta & $\begin{array}{l}\text { Entra en el } 2^{\text {do cesolfaut para dar }} \\
\text { más cuerpo al lleno. }\end{array}$ \\
\hline & $\begin{array}{l}\text { Otro medio } \\
\text { registro de corneta } \\
\text { de } 4 \text { c.p.p. }\end{array}$ & 96 caños \\
\hline $\begin{array}{r}\text { SEGUNDO ÓRGAN } \\
\text { en la Capilla }\end{array}$ & $\begin{array}{l}\text { O DE ECOS debaj } \\
\text { Real de su Magesta }\end{array}$ & $\begin{array}{l}\text { del secreto grande como esté } \\
\text { con su teclado aparte }\end{array}$ \\
\hline $\begin{array}{l}\text { Flautado de Violón } \\
\text { de } 13\end{array}$ & $\begin{array}{l}\text { Flautado de } \\
\text { Violón }\end{array}$ & unisonus del de treze \\
\hline Octava tapada & Octava tapada & Para darle más cuerpo \\
\hline Quincena & Quincena & \\
\hline Decinovena & Decinovena & \\
\hline Lleno 3 c.p.p. & Lleno 3 c.p.p. & \\
\hline Címbala 3 c.p.p. & Címbala 3 c.p.p. & $\begin{array}{l}\text { Como está la del órgano } \\
\text { principal de esta S.I. }\end{array}$ \\
\hline Trompetas & Trompetas & $\begin{array}{l}\text { Como las del realejo mejor que } \\
\text { sirve en [esta] dicha Iglesia. } \\
\text { [alude sin duda al órgano de } \\
\text { Melchor de Miranda de } 1584 \text {, } \\
\text { que, "el realejo que llaman de } \\
\text { Sevilla", reparó Quintín de } \\
\text { Mayo en 1637] }\end{array}$ \\
\hline & Corneta & $\begin{array}{l}\text { Como la de la Capilla Real de } \\
\text { S.M. }\end{array}$ \\
\hline $\begin{array}{l}\text { teclados de } 45 \text { teclas (d } \\
\text { pliegues (emmapelados } \\
\text { cada uno)- } 3 \text { secret } \\
\text { grande+corneta grande } \\
\text { de estaño fino de In } \\
\text { campanil. }\end{array}$ & $\begin{array}{l}\text { marfil los blancos y d } \\
\text { aforrados, } 1 \text { vara y } 1 \\
\text { s (órgano principal } \\
\text {-madera muy seca- tu } \\
\text { laterra) }=2 \text { registros } \\
60000 \text { reale }\end{array}$ & 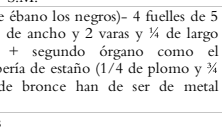 \\
\hline
\end{tabular}

DISPOSICIÓN DEL ÓRGANO DEL EVANGELIO REALIZADO PARA LA CATEDRAL DE TOLEDO POR PEDRO LIBORNA Y ECHEVARRÍA (Traza del 15-XII-1695. Escritura del 8-VI-1696). Entre [] figuran los aumentos
que se pusieron entre la escritura y el reconocimiento hecho por Sabastián Durón MANO IZQUIERDA
Teclado(s): noNO ne se alude(n) a ellos menos: "teclado a los pies"
Cadereta a la parte de adentro Con los ecos y contraecos y demás fabrica

Cuatro fuelles encajonados $[\ldots]$ con palancas $[\ldots]$ ruedas para la más comodidad de entonar [si [ÓRGANO GRANDE] caben, o sin ellas

Flautado de 26

\begin{tabular}{|l|l|l|l|l|}
\hline Flautado de 13 & (3) \\
\hline Thatado tapado] &
\end{tabular}

En cinco castillos en la fachada; los cuatro más bajos en la parte de adentro;de madera
Dentro, diapasón angosto por quedar major la voz [een lugar de otro? ¿el que hizo Octava abierta

\begin{tabular}{|l|l}
\hline Docena duplicada & Para dar mucho cuerpo al lleno
\end{tabular}

Quinzena

Diez y novena
Lleno de 5 c.p.p.

Címbala de 5 c.p.p.

Octava

Nasarte en docena

Nasarte en quincena

Seisquialtera

Diez y nobena

[recímbala]

[recímbala]

Corneta magna de 7

c.p.p.

Tolosana de 5 c.p.p.

Registro de ecos $[\ldots]$

con su acompañas

en toda la mano

Pífano M.d.
Registros de lengüeter

Trompetas reales

Trompeta magna

Bajoncillo

Clarí

[segundo clarín de

fachada]

Clarín en artiilleria

Clarín en ecos con el

anterior

orlos

Tambores (4) en alamire

y delasorre

Teclado a los pies

[ocho contras bajos

trompeta real]

Ruedas de cascabele

Otras [ruedas] de pájaro

y gaita y otros adornos

clarines

Otros adornos

Sirven para días solemnes
SEGUNDO ÓRGANO en la arte de adentro QUE HACE DE CADERETA

Flautado violón

[nasarte en $12^{\text {nat }}$ ]

[nasarte en 12

[nasarte en $15^{\mathrm{m}]}$ ]

[nasarte en $19^{\text {max }}$ ]

Trompetas

Duplicado

$1^{\text {er }}$ caño en 15 na, camo grande que a de tener el lleno mucho cuerpo

$1^{\text {er caño en } 22 \text { na }}$

Ancha de diapason

Ahusado

\begin{tabular}{|l|l|} 
& $\begin{array}{l}\text { A imitación de las que tiene el realejo } \\
\text { que sirve en la capilla mayor en la octava } \\
\text { del Corpus alude sin duda al órgano de } \\
\text { Melchor de Miranda de 1584, que, "el } \\
\text { realejo que llaman de Sevilla", reparó } \\
\text { Quintin de Mayo en 1637]. }\end{array}$ \\
\hline
\end{tabular}

\begin{tabular}{l|l} 
Cascabeles de 3 c.p.p. & Caja por detrás
\end{tabular}

Encajonado de ida y de enida $[\ldots]$ Correspondiente a la cornet

Escibe: pinfano

De metal

Unísonus con el flautado de 26

En artillería en la fachada y este a de tener ecos

[de fachada]

Encajonado arriba

de ambas manos

Para emitar $[s i c]$ a los clarines $[\ldots .$.$] que es$ han de poner, con dos registros en lo pies

[se supone que son 8 contrabajos de las trompetas reales enganchadas a las contras o independientes de ellas Sirven para días solemne Sirven para días solemnes Unisonus del flautado principal Para dar cuerpo al flautado

Cinco castillos: dos grandes a cada lado y otros dos encima pequeños y otros encima de las puertas de en medio. Caños sonantes: 14. Los otros: mudos de metal fino; [dos castillos con una tubería "muda"l

56000 reales+ 250 ducados por lo convenido en la fachada por detrás. La conducción desde Madrid a Toledo [100 ducados]: a cuenta de Pedro Liborna Echevarrí 
hizo el Padre Echevarría en la santa iglesia de Palencia", registro que ya introdujo en Cuenca en 1692 y repitirá en Sigüenza ${ }^{27}$. Para Liborna Echevarría este ha de ser en Toledo "acornetiado [sic], sera otro lleno de 5 c.p.p" (el que tiene previsto Mendoza es de 4 caños por punto), pero no alude a su fuente palentina.

Mendoza, en un órgano de dos teclados, vacila en la elaboración de los planos sonoros y no llega a una total claridad haciéndolos menos legibles. Su proyecto es o parece ser el producto de un mestizaje, herencia de su paso por Cuenca, entre las escuelas castellana y catalanovalenciana, con la duplicación de algunos registros (quincenas, decimonovenas...). Por estas fechas el clarón es un registro que abarca todo el teclado y que luego, reducido a los bajos de mano izquierda, se opondrá al registro de corneta de mano derecha. No se sabe de ningún viaje de Mendoza a Palencia: lo más seguro es que lo haya observado en el órgano del convento de San Diego de Alcalá de Henares, donde el maestro eibarrés, José de Echevarría, lo tenía previsto con un nasarte en decimonovena como guía o base de tal registro de 4 caños por punto ${ }^{28}$. Asimismo el organero lerinés se acuerda de su maestro Andueza cuando dicta que su "segundo órgano de ecos" se hará debajo del secreto grande como "en la Capilla Real de Madrid", y que en este se pondrá medio registro de corneta como la "del órgano de la Real Capilla de su Majestad".

En un órgano de teclado único - no aclara el segundo por lo menos, ya que el segundo órgano "hace de cadereta"-, Liborna Echevarría define claramente los bloques sonoros de su instrumento, como lo hará en la catedral de Segovia: flautado, nasardos, cornetas, lengüetería. Superpone los cuerpos hacia arriba de la caja: los tres secretos culminan con la caja expresiva. Mendoza, al contrario, coloca la caja expresiva en el cuerpo interno inferior, en la caja a ras del suelo. Estos cuerpos van a ser la pauta futura de la organería española. Liborna Echevarría podría vanagloriarse de pertenecer por línea directa a la escuela básica del órgano ibérico con la continuidad en la incorporación de registros antiguos como el churumbelado (que añadirá también en el de Segovia), pero no lo hace. Asimimo privilegia algunos registros de adorno cuando Mendoza los ignora en este contrato.

Finalmente se observará, como se dijo más arriba, que Mendoza alude a una autoridad anterior: la del padre del instrumento, José de Echevarría,

\footnotetext{
27 L. Jambou: Evolución..., II, n. ${ }^{\circ} 258$.

${ }^{28}$ L. Jambou: "Sebastián Durón y la 'música moderna' organística", Sebastián Durón (1660-1716) y la música de su época, Paulino Capdepón Verdú, Juan José Pastor Comín (eds.), Vigo, Editorial Academia del Hispanismo, Biblioteca de Investigación y Patrimonio Musical, 2013. En apéndice, p. 85, este artículo presenta la "Memoria de las diferencias que a de ttener el organo del Religiossimo Con[ven] to de las S[eño]ras Descalzas", cuyas "diferencias, señala este memorial, estan executadas en el organo, que se a fabricado en el convento de san Diego de Alcala, por los maestros fray Joseph de echauarria, y Bentura de echauarria su sobrino".
} 
o la de su maestro directo, Juan de Andueza. Se ve pues que Mendoza no renuncia ni a una ni a otra orientación del órgano ibérico y asume las dos líneas que parten del maestro José de Echevarría. Al contrario, Liborna Echevarría ignora sus referencias anteriores y se autoafirma como maestro único de su instrumento. Su primer gran contrato, en Toledo, es una proclama y pregón de autosuficiencia: descarta o ignora su experiencia palentina. Pero es en Palencia donde, al parecer, puede haber desarrollado unas amistades profesionales que le van a servir en Madrid en este primer contrato prestigioso. Efectivamente, en la escritura de este alude a la disposición del instrumento que se estableció el 14 de diciembre de 1695 (Documento I) gracias a Domingo Aguirre, organero que terminó el órgano del maestro Echevarría en Palencia antes de ir a Plasencia, y a Sebastián de Uron [=Sebastián Durón], que fue organista primero de la misma catedral antes de llegar a la Capilla Real de Madrid, primero como organista y después como maestro de capilla.

En la capital puede haberse relacionado con fray Martín García (sin duda Martín García Olagüe), organista del convento de la Trinidad de Madrid antes de serlo del órgano de la catedral de Cuenca recién terminado por Mendoza. Este organista está ya en relación directa con Juan de Andueza en la construcción del nuevo instrumento de su convento, en 1683, en Madrid²9; luego lo estará en Cuenca con su discípulo Domingo Mendoza, donde reconoce el proyecto del nuevo órgano catedralicio en 1692 ("un religioso de la Santissima Trinidad grande organista") ${ }^{30}$, visura el órgano nuevo de Domingo Mendoza en $16943^{31}$ así como el segundo instrumento hecho por el mismo organero en $1695^{32}$, después de haber sido nombrado organista de la misma catedral el 7 de septiembre de 169433. Es decir, que Martín García de Olagüe, en Madrid y en Cuenca, ha visto, valorado y juzgado, las dos orientaciones del órgano ibérico en el último proceso de su culminación.

No extraña que los proyectos toledanos revelen las dos orientaciones suscitadas por la acción de José de Echevarría. Domingo Aguirre y Sebastián Durón apoyarían por un lado el proyecto de Liborna Echevarría. Martín García Olagüe, como posiblemente Andrés Lorente ${ }^{34}$, organista y teórico, tomarían partido por Domingo Mendoza. Estas afirmaciones, condicionales, son nuestras pero no dejan de deducirse de los textos contemporáneos $\mathrm{y}$ de las relaciones que se establecen entre los hombres del oficio.

${ }^{29}$ L. Jambou: Evolución..., II, n. ${ }^{\circ} 210$, p. 91.

${ }^{30} \mathrm{Ibid}$., n. ${ }^{\circ} 230$ a, p. 103; L. Jambou: "Organeros en la diócesis de Cuenca en los siglos XVI-XVIII", Almud, 4, 1981, pp. 154-155.

${ }^{31}$ L. Jambou: Evolución..., II, n. 231 c, p. 105; id.: "Organeros en la diócesis de Cuenca ...".

$32 \mathrm{Ibid}$., n. ${ }^{\circ} 232$ b, p. 106; id.: "Organeros en la diócesis de Cuenca ...".

${ }^{33}$ L. Jambou: "Organeros en la diócesis de Cuenca ...", p. 155.

${ }^{34}$ Véase nota 39. 
Por cierto, la línea directa José de Echevarría-Liborna Echevarría con Domingo Aguirre y luego su discípulo Manuel de laViña, no adopta en un primer tiempo el "órgano de ecos" a ras del suelo y en el entablamento inferior con un crecido grupo de registros sino que las "Diferencias de los ecos" se reducen a dos o tres registros (corneta, clarín y flautadillo) situados encima del secreto principal y encerrados en su caja expresiva. Así lo hizo el maestro en San Diego de Alcalá de Henares y así lo hará el discípulo, Liborna Echevarría, en el órgano de la Epístola de la catedral de Segovia. Es verdad que estos órganos son "a solo un teclado", cuando los de Andueza y Mendoza se orientan desde el principio hacia instrumentos de dos teclados. Así los construye Andueza, quizá para la Magistral de San Justo y Pastor de Alcalá de Henares, sin duda para el órgano del Palacio Real, luego para el convento de la Trinidad de Madrid y que continúa proponiendo Mendoza en Toledo, después de sus realizaciones conquenses, en 1692-169535. Quedan aún muchas dudas, ya que Mendoza no puntualiza siempre en su descripción técnica si todos los registros que están en el "organo de ecos" funcionan en una caja expresiva. En Toledo parece que sí, mientras que en Sigüenza, además de los registros "de la cadereta que va a la parte de adentro" -que no se sabe si están encerrados en su caja expresiva-, lleva una corneta y un flautadillo que sí están en su caja encima de los demás secretos.

Queda de manifiesto que en torno a 1700 se afirman dos orientaciones en la organería española, la de Pedro Liborna Echevarría y la de Andueza y Mendoza, nacidas del mismo tronco que es el de José de Echevarría. La línea de Liborna Echevarría se expande hacia el sur, con Domingo Aguirre en Sevilla en 1720 después de sus construcciones en Plasencia y sus excursiones por el norte aragonés, y hacia el noreste, hasta Santiago de Compostela, con Manuel de laViña, discípulo suyo. Con Mendoza, discípulo de Andueza, parece agotarse en torno a 1730 la línea lerinesa que arranca en Alcalá de Henares.

A continuación es de interés intentar seguir la línea lerinesa hasta la catedral de Murcia, sus prolongaciones hacia la costa mediterránea y sus anteriores enlaces con Valencia.

\section{Una tercera orientación: el temperamento pretonal del grupo Echevarría-Andueza-Mendoza}

Lo que antecede dibuja, con algunos rasgos diferenciadores, dos orientaciones del órgano español. Estos rasgos no bastan para afirmar que sean dos escuelas distintas, pero son suficientes para definirlas mejor, sobre todo

\footnotetext{
${ }^{35}$ L. Jambou: Evolución... ; id.: "Julián de la Orden: culminación sonora de la organería en Cuenca", Il Libro de la 48 SMR, Cuenca, Semana de Música Religiosa, 2009, pp. 89-133.
} 
a partir del contrato de Mendoza con la catedral de Sigüenza en 1700 que ya se conoce. Lo que sigue es una aproximación para sugerir y afirmar, a partir de los documentos, una tercera orientación, la del grupo Echevarría-Andueza-Mendoza, que representa, por la esencialidad del parámetro en que actúa, el temperamento, una nueva escuela que se limitó a la afirmación de una expansión pretonal.

Leamos dos textos fundamentales de José de Echevarría ${ }^{36}$. El primero es del año 1683 y prevé la disposición del órgano de la iglesia mayor de Tolosa:

Lo primero es de advertir que el juego de teclas que el dicho órgano ha de tener, no será conforme a los que hasta ahora se han usado por el reconocimiento que ha habido entre maestros peritos en el arte de la música [pues en ellos hallandose a muchas inperfecciones como se ha experimentado, por faltar al rigor que la musica como se a experimentado] hasta que con comunicación y estudio bien largo, tome otra forma, llevándome no sólo la curiosidad, mas sí reparando ser muy importante que los órganos estuvieren bien cavales, por todo género de acompañamientos (sin suplefaltes). Bien se sabe que en muchos tiempos se ha usado de harpa de una orden [y por lo narrado se an executado fuesen de dos Ordenes] (y aun así están faltos los acompañamientos). Supuesto lo dicho cuando fui llamado al convento del glorioso San Diego de Alcalá de Henares, puse por execución en el órgano de dicho convento a que llevase un teclado con las circunstancias que pide la música y son en número cincuenta y ocho teclas. Que estas las necesita si es que ha de quedar con la perfección debida.

El segundo no tiene fecha pero es sin duda del mismo año de 1683. Figura en la última parte del "Memorial de las diferencias que ha de llevar un órgano rumboso, siéndolas muy necesarias y sobresalientes". El memorial está firmado por "Fr. Joseph de Hechabarría" y la claúsula final, que transcribimos, por "Joseph de Echebarría", discípulo y colaborador de su maestro homónimo.

También se advierte que el teclado no ha de ser de los comunes [esto es], que en el negro de Gesolreut [sustenido] haya otro negro que forma tercera menor desde el fefaut blanco. Lo mismo ha de haber otro negro en el bemolado de elami,

36 José Antonio de Donostia: "El órgano de Tolosa (Guipúzcoa), del año 1686", Anuario Musical, X, 1966, pp. 123 y 127. La transcripción hecha aquí se ha basado en esta publicación. Ver también la tesis de Marco Aurelio Brescia: Lécole Echevarría en Galice et son rayonnement au Portugal, Universidad de París IV-Sorbonne-Universidad Nova de Lisboa, 2013, vol. II, apéndices, pp. 28 y 34 . El tema de la tesis versa sobre la actuación de Manuel de la Viña. Transcribe los textos de manera diplomática respetando la grafía original de las escrituras que se ponen aquí entre corchetes. Este trabajo no llega, sin embargo, a declarar, en su estudio o documentos, la orientación tomada por De la Viña. También en José María Barrero Baladrón, Gerard A. C. de Graaf: El órgano de Santa Marina la Real de León y la familia de Echavarría, organeros del rey, León, Universidad de León, 2004, p. 134, transcribe parte de la primera de estas citas. También L. Jambou en Evolución... insiste en las citas sin transcribirlas del todo, pp. 231232 y en "Aproximación a una geografía de la 'música moderna' organística. 1660-1710", De música hispana et aliis, Miscelánea en honor al Prof. Dr. José López Calo. S.J., Emilio Casares Rodicio, Carlos Villanueva (coords.), Universidad de Santiago de Compostela, 1990, vol. I, pp. 661-662. Ver nota 40. 
para que tenga subsistencia la cláusula final del tercer tono, y esto en todas sus octavas. Y es estar los órganos con la perfeccion que pide la música.

Sería largo y fuera del ámbito de este estudio desvelar el contenido de las dos citas. Lo que sí conviene destacar enseguida, aunque en los textos de Echevarría aparecen como innovaciones recientes o propias, que estas pertenecen a una tradición, aun sensible en el propio léxico usado por el organero en el cual sale a menudo el vocablo "género". Echevarría bebe aún de las preocupaciones humanísticas y renacentistas de finales del XV y, sobre todo, en cuanto a hechura instrumental, del siglo XVI, en el cual aparecen la figura italiana de NicolaVicentino (en su Musica ridotta alla moderna prattica de 1555) y, en España, la de Bermudo (en su Declaración de instrumentos musicales... de 1555) y, luego, la de Salinas (en De musica librii septem, 1577). Todos ellos están preocupados por dar nueva vida a los conocimientos, musicales en este caso, de la antigüedad. De ahí su preocupación por que renazcan los géneros de la música antigua: los géneros diatónico, cromático y enarmónico. Parece que en el caminar de las formulaciones y realizaciones teóricas, en más de un siglo, José de Echevarría culmina un ciclo, más práctico que téorico en su caso, de división interválica del tono. La extensión de su teclado instrumental quiere pasar de los géneros y ámbito diatónico o cromático para adentrarse en lo microtonal gracias al género enarmónico. De ahí que sus teclados no sean "comunes", que son de 42 teclas (a veces ya de 45), y lleguen a una extensión de 50 o 53. Sus construcciones más prestigiosas llegan a una u otra de estas extensiones (convento San Diego de Alcalá de Henares, iglesia matriz de Tolosa, iglesia mayor de Santa María de la Redonda de Logroño, convento de las Descalzas Reales de Madrid, catedral de Palencia ${ }^{37}$ ). Estas son consecuencias de unas preocupaciones musicales, pero más prácticas y funcionales, es decir, de los propios organeros o constructores de instrumentos de teclado, para que "no falten las posturas de todo género de acompañamientos" "38, que de las de los tratados teóricos musicales, nacidas más de la especulación y del cálculo que de la práctica.

En estos ejemplos se nota finalmente que de las reflexiones y acción de los dos José de Echevarría ${ }^{39}$ nace una tercera dimensión del órgano ibérico: no solo la trompetería horizontal o tendida, no solamente el sistema

\footnotetext{
${ }^{37}$ Marco Aurelio Brescia: Lécole Echevarría en Galice..., vol. I, pp. 42 y 44.

38 L. Jambou: "Sebastián Durón...", p. 86.

${ }^{39}$ Confundimos así, por el contexto, a los dos Echevarría, al fraile y a su sobrino. Lo cierto es que convendría separarlos más claramente (ver en L. Jambou: Dictionnaire...) notando desde el principio que, muerto el maestro en Palencia, es su sobrino quien parece que visura o subsana las orientaciones del fraile: esto es notorio en Cuenca y en Sigüenza (después de obras realizadas por Domingo Mendoza). Pero de momento por lo menos se ignora el trabajo que efectúa en los órganos de las catedrales de Sevilla y, sobre todo, de Burgos.
} 
expresivo de los ecos sino también el resurgir del teclado enarmónico de los instrumentos de teclado. Este parámetro lo afirma y realiza José de Echevarría, pero no pasará del embate del sistema armónico, el de la tonalidad clásica, que se impone ya y domina todo el siglo XVIII. Sin embargo, este reinvento del franciscano sigue un camino que es el de parte de sus discípulos directos o indirectos, el de Andueza y Mendoza ${ }^{40}$.

\section{Actuaciones y realizaciones enarmónicas de Juan de Andueza y Domingo Mendoza}

Las actuaciones de Juan de Andueza se desarrollan durante un período bastante corto y abarca desde 1669 hasta 1686, año en que muere. Sus realizaciones las conocemos ${ }^{42}$ en parte o en la totalidad a través de los textos, y en ninguno de ellos alude si ha seguido o no esta tercera orientación. Su relación con el maestro eibarrés ("discípulo mío" dice Echevarría) queda clara, pero no así las que tiene este con Félix de Yoldi (desconocido por él pero que, pese a sus indebidas apropiaciones de inventos que en realidad son suyos, recomienda para la hechura del órgano de Logroño $\left.{ }^{43}\right)$. Sus órganos son instrumentos realizados sobre todo para localidades rurales y con presupuesto limitado (con excepción de los de la Capilla Real, las colegiales de Alcalá de Henares y de Talavera de la Reina): Torrelaguna, Alcalá de Henares (iglesia de Santiago), Méntrida, Madrid (iglesia del convento de la Trinidad), Almonacid de Zurita, Siete Iglesisas o Driebes. Se puede dudar de su afán por alcanzar los deseos de su maestro: sus teclados no pasan del ámbito de 42 o, como máximo, de

\footnotetext{
${ }^{40}$ Ver la tesis de Andrés Cea Galán: La cifra hispana: Música, tañedores e instrumentos (siglo XVI-XVIII), Madrid, Universidad Complutense, 2014, pp. 335, 851, 857 y 895 en la que aborda minuciosamente el problema.

${ }^{41}$ El órgano hecho por Jorge de Sesma para la catedral de México no parece haber seguido esta vía. Ver José Antonio Guzmán Bravo: "Documentos inéditos para la restauración de los órganos históricos de la Catedral Metropolitana de Nuestra Señora de la Asunción, de México Tenochtitlán (1688-1736)", Anuario Musical, 62, 2007. Edward C. Pepe: "An Organ by Jorge de Sesma for Mexico City Cathedral", Revista de Musicología, XXIX, 1, 2006; id.: "The Installation by Tiburcio Sanz and Félix de Yzaguirre of the Jorge de Sesma Organ for Mexico Cathedral: 1692-95“, Revista de Musicología, XXIX, 2, 2006. Valdría la pena ahondar más en el recorrido profesional de los organeros Sesma y de modo peculiar en Jorge, asentado en Madrid en 1687. Sin duda, en contacto, ¿inspirándose?, con los José de Echevarría y Mendoza, y luego con Pedro II Liborna Echevarría: son datos que quedan por comprobar.

42 La mayoría de ellos están en L. Jambou: Evolución..., II, entre las pp. 85 y 97 los n. ${ }^{\circ}$ 198, 202204, 208, 210, 215-219. De la hechura del órgano de la capilla del Palacio Real, de 1675, no se conoce nada en concreto. Ver también Juan Antonio Marco Martínez: El órgano histórico en la provincia de Guadalajara, Guadalajara, Diputación Provincial, 1990, p. 259. Es de notar que el teórico Andrés Lorente, organista de la Magistral de Alcalá de Henares, reconoce el órgano de la iglesia Santiago de Alcalá el 25XII-1669 terminado por Juan de Andueza en 1679 (n. ${ }^{\circ}$ 198). Más adelante, en 1692, Andrés Lorente recomendará a Domingo Mendoza con añadidos suyos (n. ${ }^{\circ} 230 \mathrm{~d}$ : "Un grande organista que ay en Alcalá") para la fábrica del órgano de la catedral de Cuenca.

${ }^{43}$ J. M. Barrero Balandrón; G. A.C. de Graaf: El órgano de Santa Marina de León..., pp. 230-231.
} 
45 teclas. Por cierto, se desconocen los detalles técnicos de su actuación en el órgano de la Capilla Real e, incluso, en el nuevo de la colegiata de Talavera la Reina. Pero el que José de Zaragoza, valenciano y profesor de matemáticas en el Colegio Imperial de Madrid, le anime en 1675 a construir un órgano pequeño con temperamento igual, es revelador de que el joven lerinés seguía ya un camino distinto, quizás más próximo a la vía protonal de su maestro eibarrés ${ }^{44}$.

Domingo Mendoza, discípulo de Andueza, afirma mejor este camino y su tercera orientación. Encargado de rematar los órganos comenzados por su maestro (en las provincias actuales de Madrid y Guadalajara: Siete Iglesias, Almonacid de Zurita, Driebes) termina su servicio, su aprendizaje y sus obligaciones el 30 de noviembre de 1686, recibiendo de Sebastiana de Ávila, viuda de Juan de Andueza, la cantidad de 720 reales ${ }^{45}$. Su primer gran contrato conocido lo tiene en 1692 con el cabildo de la catedral de Cuenca. Los teclados de sus instrumentos hasta 1700 conllevan 45 teclas, incluyendo el de la catedral de Toledo en 1695; en Sigüenza uno tiene 47 y otro 45 teclas. Entre 1700 y 1701 construye el instrumento de la catedral de Ávila. Aunque su contrato se desconoce, en 1856 Juan de Castro deja una descripción de un instrumento de la catedral de Ávila que data del siglo XVII; pese a que no figure ningún nombre, no puede ser, en nuestro opinión, otro que el de Mendoza. En él declara Juan de Castro (veáse Apéndice, documento II):

[p. 136r] También se hallaban [en el siglo XVII] órganos con algunas teclas accidentales dobles como las ya referidas en el siglo anterior al hablar de la pretendida constitución armónica del órgano. Así pues [entre rayas: en] el órgano que la catedral de Ávila se hallaba del lado del Evangelio anteriormente al que ahora existe había la particularidad de tener dos teclas negras en todos los intervalos de segunda mayor que forman las notas $\underline{\text { re }} \underline{\text { mi y }}$ sol: la una de ellas servía para el [p. 137] re sustenido, y la otra para el mi bemol; y las otras, asimismo servían la una para hacer el sol sustenido y la otra para el la bemol.

En 1710 Mendoza se compromete a construir el órgano de la catedral de Murcia. En su contrato llega a añadir tres teclas por punto a sus dos teclados de 53 caños por punto. Aunque no quede claro el significado, estas notas serían: Re sostenido, La bemol y La sostenido:

Es condizion que en dho horgano viexo se le han de añadir en cada Rexistro los caños que pertenezen a los tres puntos que se añaden en el òrgano que se haze nuebo.Y el primero un bemol de elami de los primeros baxos. Y que en el un

${ }^{44}$ C. Bordas, L. Robledo: "El arcón de José Zaragoza: ciencia y música en la España de Carlos II", Nassarre, XV, 1-2, 1999, p. 274.

${ }^{45}$ L. Jambou: Evolución..., II, n. ${ }^{\circ} 219$, p. 97. 
flauttado maior sea de Madera.Y en todos los Rexistros de estaño; los ôttros dos punttos son el vemol de Alamire tenor y susthenida en Alamire del Conttraltto que en todos son sesenta y un $\operatorname{caños}^{46}$.

Esta cláusula deja claramente diferenciada la condición de bemolada o sostenida de las notas afectadas por el cambio y aumento de tesitura de los teclados, entre lo viejo y lo nuevo, entre las notas con bemol o con sostenido.

La zona de Murcia-Albacete parece haber sido durante las primeras décadas del siglo XVIII lugar de encuentros de organeros y, así, tierra abonada para la implantación de esta orientación, a pesar de la escasez de documentos. En 1710 Mendoza realiza el órgano catedralicio murciano; en 1728 Miguel Alcarria del Cañizo propone un proyecto para la iglesia de San Juan de Albacete lo mismo que Juan de la Orden; en 1736 Francisco Campoy, oriundo de Alcoy (Alicante) y colaborador de Francisco (Fulgencio Llop) en Lorca (Murcia), propone un órgano nuevo para la misma iglesia y empieza a realizarlo. Miguel Alcarria del Cañizo tiene variados asentamientos, todos ellos conquenses. Juan de la Orden es oriundo del pueblo conquense de Barchín del Hoyo y es cabeza del linaje emblemático de Cuenca. Patricio Campoy es oriundo de Alcoy y Fulgencio Llop, oriundo de tierras valencianas, actúa en estas tierras así como en las de Murcia y Andalucía.

Precisamente Fulgencio Llop propone en 1716 para la colegiata de Lorca (Murcia) un teclado de 50 notas porque

se le ha de añadir dos mas, la una servirá para substenido de D.La.Sol. Re, puesto en la parte baxa de el bemol de E.La.Mi. Re. grave; la otra que asimismo haya en dicho órgano, bemol de A.La.Mi.Re. sobre agudo, puesto en la parte alta de el sustenido de G. Sol. Re.Ut. que una y otra son muy nezesarias, con que tendrá dicho teclado 50 teclas $^{47}$.

En este ambiente no extraña que Patricio Campoy emita en 1736 un juicio sobre el proyecto de 1728 de Miguel de Alcarria del Cañizo revisado por el organista de la catedral de Murcia, Pedro Muñoz Montserrate, en que puntualiza, para que el órgano quede completo:

Más un teclado de quarenta y seis teclas porque ha de llebar sustenido en fa, la, sol, re agudo" [...] "mas se han de hazer dos secretos de madera de pino, seca y segura, con quarenta y seis canales para colocar dicha música $[\ldots]^{48}$.

${ }^{46}$ E. Máximo: "La renovación de los órganos de la catedral de Murcia (1661-1726)", El comportamiento de las Catedrales españolas. Del Barroco a los Historicismos, Murcia, 2003, p. 249; también editado en Nassarre por Cristina I. Pina Caballero: "Órganos y organeros en Murcia entre los reinados de Felipe V y Carlos III: algunas fuentes documentales", Nassarre, XXII, 2006, p. 512.

${ }^{47}$ E. Máximo: "Armónicos ámbitos: Los órganos de San Juan de Albacete", separata del segundo congreso de historia. Vol. II, Edad Moderna, Albacete, Instituto de Estudios Albacetenses Don Juan Manuel, Diputación Provincial de Albacete, 2002, p. 388 y nota 50.

${ }^{48}$ Ibid, p.391. 
Finalmente es Patricio Campoy quien realizará este instrumento a partir de una planta definitiva diseñada en 1736, aconsejada por el organista Pedro Muñoz de Montserrate, y la licencia episcopal firmada el 15-I-173749.

Lo que se observa en los escasos ejemplos anteriores es que la amplitud del teclado es variable: 46, 47, 50, 53 teclas. Esto podría llevar a varias consideraciones, prácticas y teóricas, a partir del teclado común de 42 teclas, aunque no vamos a entrar aquí en ellas. Lo que conviene resaltar para nuestro propósito es la naturaleza de las teclas que destacan los contratos. Casi siempre se trata de Re sostenido y de La bemol y, además, alguna vez del La sostenido. Las notas correspondientes a estos apelativos figurarían visualmente en el teclado de la época y se desarrollan en su teoría musical, pero se confunden en nuestro teclado y solfeo modernos. Son notas diferenciadoras, enarmónicas, Re\#, La\# y Lab complementarias de los Mib, Sib y Sol\#. Son estas las notas ${ }^{50}$ que quieren realizar estos constructores de instrumentos de teclado en sus realizaciones de finales del XVII y principios del XVIII. Estas propuestas enlazan y conectan con preocupaciones anteriores del Renacimiento y sus teóricos -en latín o en lengua vulgar- y las de todo el siglo XVII.

Si se consideran las zonas geógráficas en las cuales se manifiesta esta característica, se nota que estas - por oriundez o vecindad de los organerospertenecen a una amplia región con nacimiento en Navarra-País Vasco, asentamientos y realizaciones espóradicas en Alcalá-Talavera-Madrid sin poder infiltrarse de modo eficaz en el centro toledano, y que su mayor potencialidad expansiva es el flanco suroriental de la península, es decir, las actuales provincias de Murcia y Albacete.

\section{Enlaces con el centro de Valencia}

Para completar este intento de trazar un mapa del temperamento de los teclados instrumentales a finales del XVII no se puede dejar de considerar y completar, en la época de Cabanilles, lo que pasa en el centro valenciano con la incursión en Cuenca de los organeros Roque Blasco y José Beltrán, su sobrino, después del trabajo de Domingo Mendoza.

En primer lugar llama la atención un artículo minuciososo de Joaquín Piedra, aunque incompleto, sobre la música en el Colegio del Corpus Christi ${ }^{51}$. Durante la segunda mitad del siglo XVII rige la organistía del ColegioValero

${ }^{49} \mathrm{Ibid}$, p. 388. Campoy muere el 5-X-1741 dejando una viuda, Mariana Rosique, y antes de concluir el instrumento.

50 El número de tubos queda también modificado por estos añadidos; lo tenemos en cuenta aunque no lo hayamos estudiado a través de los contratos existentes.

${ }^{51}$ J. Piedra: "Organistas valencianos de los siglos XVII y XVIII. A-Organistas del Colegio del Corpus Christi" [el B firmado por José Climent, está dedicado a los organistas de la catedral], Anuario Musical, XVII, 1962, pp. 179-208. 
Barrachina, de cuya vida se conoce poco, pero que merecería alguna atención por sus escritos ${ }^{52}$. Pertenece a una generación de músicos anteriores a la de los novatores valencianos de finales de siglo. Anclado al parecer en sus principios teóricos, forma parte de oposiciones a plazas de músicos, tanto en el Colegio como en otros templos. Sus informes, a veces de su puño y letra, están, segun Piedra -reflejo del interés musicológico de la época-,"repleto[s] de farragosas digresiones teorizantes [...y] muestra de su ideología borrosa", de lo que transcribe un ejemplo: el de un tiple, Pedro Martínez de Orgambide, que concursa en 1686. Su parecer se fundamenta en la definición de una "perfecta música" que se abre a dos partes del "número sonoro" 53 : tanto la tradición teórica que remonta a san Agustín, san Isidoro o san Gregorio Magno, como a los compositores prácticos que pertenecen todos a la polifonía renacentista, entre los cuales cita a: "Felipe Rogier, Morales, Palestrina y otros". Basado en esto formula su dictamen en los términos siguientes:

estas partes me sirvieron de pauta para venir en conocimiento perfecto, en razón, fundado en la parte del número (que es lo que conviene al entendimiento) formó el examinado en sus tránsitos de tono mayor e iguales, semitono mayor y menor y otros tránsitos con todo acierto ; en la parte de sonoro, que es la [p.160] que conviene al oído, uniforme a los instrumentos, y perfecta afinación, la voz para el caso ; plausible: de un mismo aumento los puntos que forma desde Gesolreud, asta su octava.Voz de pecho que es la permanente, por ser perfecta. respecto de la voz de garganta y cabeza, que por aver ofrecido brevedad en la primera cláusula deste contenido, no ago descripción de ellas por menudo. El rodeo es bueno, el modo de vestir los papeles como Maestro de mucha inteligencia, el Diesis que forma o trinado, por otro nombre ; en comparativo grado, pospuesto al superlativo. Desde la octava dicha forma quatro puntos mas altos, sonoros.Y asi en los de voz, como en los falsetes vastante cuerpo para dúo tercio y un quarto, que es lo que se puede desear, grandísima destreza $[\ldots] . .^{54}$

No cabe duda de que en estos informes pueden caber unos valiosos pareceres sobre el saber musical teórico esperado por un miembro del tribunal, sobre el nivel de estudio de los opositores, sobre sus ejecuciones y así como sobre el nivel interpretativo, tanto vocal como instrumental de que es carente el aparato crítico de hoy ${ }^{55}$.

52 Además del artículo anterior de J. Piedra, véase también F. Pedrell: Diccionario biográfico y bibliográfico de músicos y escritores de música españoles, Barcelona, 1897, pp. 138 y 164; J. Ruiz de Lihory: La música en Valencia, Valencia, 1903, p. 177; J. Piedra: "Maestros de capilla del Real Colegio de Corpus Christi (1622-1822)", Anuario Musical, XXIII, 1968, pp. 61-127.

${ }^{53}$ Este sintagma figura en el primer trabajo publicado de A. S. García Pérez: El número sonoro. La matemática en las teorías armónicas de Salinas y Zarlino, Salamanca, Caja Duero, 2002.

${ }^{54}$ Las referencias del archivo del Corpus, en el artículo de J. Piedra, son las siguientes: A.P., I, 6, 8, 89.

55 Tenía previsto revisar en julio de 2015 el legajo concerniente a este músico en el mismo archivo. Tanto el estado actual de parte del archivo, falto de nuevo inventario, como otros motivos nos apartaron de ello. 
Al mismo organista, mosén Valero Barrachina, se le llama en 1694 para visurar y examinar un órgano construido por Roque Blasco para la iglesia del convento de Santo Domigo de Valencia. En este informe se muestra el organista tan meticuloso y escrupuloso por el ejemplo citado, como en las oposiciones que presenció. Su plan de visura se divide en dos partes: uno ideal en 12 partes -que el "trabajo, desvelo y experiencia [le] han adotrinado"examina las distintas estructuras del instrumento y el segundo, también en doce puntos, aplica este plan al instrumento de Santo Domingo, no olvidando el examinador en pedir con antelación la capitulación entre el maestro Blasco y el convento con el fin de "hazer perfecta la relación". Barrachina pide, limitando la lectura al objeto de nuestro estudio, en su plan inicial:

2- Que el teclado cada uno en su género esté igual, y en la pulsación no aya más resistencia en unas teclas que en otras.

En la segunda parte Valero Barrachina comenta lo que ha observado en el órgano del convento dominico:

2- Lo contenido en el número segundo que esté el teclado igual, y en la pulsación no aya más resistencia en unas que otras teclas he hallado uno y otro con el arte que deve estar según buena música y arte de bien medir, puse toda atención en los tres géneros que tiene la música y hallé en el diatónico todos los intervalos que se reducen a dicho género perfecto; en el género armónico su división la hallé con perfección, en el género cromático, assí mismo todas sus divisiones, perfectas, con que doy por bueno, ygualdad de teclados, cada uno en su género, y yguales en pulsación ${ }^{56}$.

El que Barrachina examine el órgano según los "tres géneros" musicales, que encuentra "perfectos"' deja suponer que el organero Roque Blasco participaba igualmente de esta corriente de realizaciones enarmónicas. El examen del recorrido de sus actuaciones, particularmente a partir de 1682 en la iglesia San Martín de Valencia, donde realiza un instrumento con modificaciones significativas entre 1682 y 1688, permite suponer que tuvo relaciones con los movimientos que animaban a los organeros nacidos en el centro vasco-navarro. Terminamos con esta hipótesis que deja en el aire muchos interrogantes que merecen alguna explicación aclaratoria.

La primera cuestión sería averiguar la posible relación de Roque Blasco con el centro castellano, ya que perteneciendo al área catalano-valenciana sería más lógico que heredase las tradiciones de su propia escuela antes de

${ }^{56}$ Cabanilles. Revista trimestral de la Asociaciòn Cabanilles de Amigos del Órgano (Vicente Ros, dir.), n. ${ }^{\circ} 22$, abril-junio 1987, pp. 19-22 (545-548); la visura del órgano se comenta brevemente en L. Jambou: "La obra de Juan Bautista Cabanilles entre dos estéticas sonoras", Joan Cabanilles culminación de la música barroca hispánica. Congreso conmemorativo del III centenario de su muerte (Valencia, 9-IV-1712), Valencia , 21/23-XI-2012 (en prensa). 
explorar lo que pasa en el centro castellano. Esto sería más lógico tanto más cuanto que Valencia fue testigo en la catedral y en el Colegio del Corpus Christi,de los últimos instrumentos del organero de referencia de la escuela feneciente mediterránea, de la mano de la figura de su creador,Antonio Llorens. Aunque se puede discutir en cuanto a sus realizaciones, se conocen las características de los teclados, la amplitud de los mayores instrumentos del siglo XVI, que calificamos de enarmónicas aunque no salga el término en los textos. En todo caso, esto no explicaría que Cuenca, al apartar a Mendoza en la reelaboración de sus órganos, no llamase en 1696 a otro constructor del centro castellano que se haya apropiado ya de las técnicas del nuevo órgano. Pero tanto, el retorno de Blasco a las fuentes del siglo XVI como aclaración sobre los motivos de sus realizaciones en San Martín de Valencia, durante un periodo largo que abarca los años 16821688 , podrían explicar su tercera orientación. Esta se manifiesta de manera casi explícita en la visura del órgano del convento de Santo Domingo de Valencia en 1694 hecha por el oscuro Valerio Barrachina ${ }^{57}$.

No se agotan con ello las indagaciones que se pueden hacer en torno al centro valenciano. Durante la segunda mitad del siglo se conoce la reflexión científica de un grupo de valencianos, los llamados novatores, entre los cuales hay dos téoricos que se preocupan por la música. Uno de ellos es Félix Falcó de Belaochaga, que había fabricado en Valencia un tetracordio con el fin de facilitar la entonación de claves y órganos. El segundo es José Zaragoza, jesuita que figura en el profesorado del Colegio ilmperial de Madrid. En 1675 José Zaragoza propone al organero Juan de Andueza -que está acabando el órgano de la Capilla Real- que construya un órgano pequeño y que realice un teclado con octavas divididas en doce partes iguales, es decir con "temperamento igual" 58 . Esta sería la orientación que tomarían los Liborna-Aguirre. No se sabe si esta recomendación de Zaragoza llegó a cuajar y a realizarse, por Andueza u otros, pero su deseo es ya indicativo y señal, negativa, de lo que adelantábamos: Andueza estaba realizando instrumentos enarmónicos, de la tercera orientación. Por otra parte, todo parece indicar que, en la costa mediterránea, en la capital Valencia hubo en la construcción instrumental musical varios niveles distintos entre los cuales se enfrentaban, principalmente, los partidarios de los avances

57 Ibid

${ }^{58}$ C. Bordas, L. Robledo: "El arcón de José Zaragoza...", p. 274; hemos descartado de este trabajo cualquier alusión al temperamento igual de las cuerdas pulsadas, como la vihuela o la guitarra. Sobre el temperamento igual de los instrumentos de cuerda hay muchas afirmaciones, pero conviene consultar el último ensayo sobre el tema (que puntualiza certeramente "instrumentos de cuerda 'con trastes"'), A. S. García Pérez: "El temperamento igual en los instrumentos de cuerda con trastes", Francisco de Salinas: música, teoría y matemática en el Renacimiento, Amaya García Pérez, Paloma Otaola (dir.), Salamanca, Universidad de Salamanca, 2014, pp. 61-90. 
armónicos, a través de las afirmaciones acústicas recientes, y los partidarios de la tradición, como la de Barrachina y la de Joan Cabanilles, sin duda, heredada del Renacimiento y reinterpretada para uso musical y funcional. Este uso funcional se notaría más en los acompañamientos del canto gregoriano, improvisados, que en obras solistas, de las que apenas quedan ejemplos escritos ${ }^{59}$.

Como se sabe, esta reinterpretación empezó ya en el siglo XVI, cuando Bermudo pide al organista que para el transporte del modo I en Fa se baje el La para que suene La bemol con el fin de diferenciarlo del Sol sostenido, ya existente en el teclado. La categoría enarmónica de este La bemol no ofrece duda en este momento del descubrimiento de los géneros de la música antigua. Sobre esta cuestión es obligado citar a Salinas quien, precisamente sobre este punto, declara:

[...] Aconsejo vehemente a todos los fabricantes de instrumentos, como ya he hecho antes [p. 293], que si en dichos instrumentos, especialmente en los órganos, no quieren dividir los semitono mayores en menores y diesis, como lo exige el género enarmónico, debido a la multiplicidad de sonidos existentes, al menos en dos de los cuatro diapason[es] que contienen los órganos, esto es, los diapasón $C$ mayúscula $c$ minúscula, y $c$ minúscula doble $c$, no tenfan miedo de añadir dos sonidos: uno el $D$ enarmónico sostenido, entre el $D$ diatónico y el $E$ cromático, para que el $E$ diatónico tenga debajo de sí un semitono mayor; y otro el $a$ mol, entre el G cromático y el a diatónico, para que el G diatónico tenga encima de si un semitono mayor. Añadidos, pues, estos cuatro sonidos, los organistas podrán acompañar cómodamente al coro de cantores, ya que el primer modo los encuentra en $F$ o en el $E$, y el cuarto en el $G$, y los restantes de modo semejante a estos $[\ldots]^{60}$.

Como se ve, en el siglo XVI Salinas anima a que se construyan instrumentos con $a$ bemol y $D$ sostenido, precisamente las notas ausentes de los teclados comunes. Los organeros no podían encontrar mejor abogado. Quizá sea esta una vía callada de la posible y poco conocida difusión de las obras de Salinas. En todo caso es una recomendación que recogen los fabricantes que forman el grupo Echevarría-Andueza-Mendoza. Señalamos finalmente lo que puntualiza aquí y en otros textos ${ }^{61}$ el teórico salmantino: "los organistas podrán [así] acompañar cómodamente al coro de cantores". El coro de cantores alude aquí no tanto a la Capilla de música,

\footnotetext{
p. 880 .

${ }^{59}$ Andrés Cea Galán: La cifra hispana..., alude a ellas y a sus anotaciones gráficas, por ejemplo en

${ }^{60}$ F. Salinas: Siete libros de música, I. Fernández de la Cuesta (ed.), Madrid, Alpuerto, 1983, p. 301. Ver también, en la misma edición pp. 166, 238 y 403-404.

${ }^{61} \mathrm{Ibid}$., p. 166: "para que los que tocan el órgano pueden acompañar más fácilmente al coro de cantores"; p. 404 declara: "[...] en ciertos órganos que tienen un tercer teclado para poder acompañar más fácilmente a los que cantan en el coro", dando como ejemplo el órgano del monasterio de Santa Maria Novella de Florencia.
} 
especializada en canto de órgano o polifónico, como al conjunto de los que formaban parte del coro (canónigos, racioneros, beneficiados... y los cantores de la Capilla de música) dedicado al canto llano, lo mismo que en Bermudo. Queda más claro así que esta clase de órganos enarmónicos permitía el acompañamiento del canto gregoriano mientras que los otros, los de la segunda orientación protonal, lo hacían dificil. También se entienden mejor, en pleno período tonal, las polémicas suscitadas por este acompañamiento, de modo agudo en Francia durante el segundo tercio del siglo XIX ${ }^{62}$.

En relación con los contratos y ejemplos citados extraña que la extensión de los teclados no se explicite siempre y se dé por supuesta, de forma que no se llega a clasificar la calidad del instrumento ni tampoco a visualizar los teclados. Se puede dudar, incluso, del número de caños y teclas declarado por los contratos. No se sabe ${ }^{63}$ si la tecla añadida se hace duplicada y paralela, duplicadas pues a las existentes, o si se fabrica prolongando y partiendo la tecla negra, única y existente ya, sea bemolada o sostenida ${ }^{64}$.

Este punto hace pertinente una última reflexión sobre la transmisión documental como verdad histórica, documento "auténtico" de los escribanos, frente a la realidad contemporánea. El documento transmite una realidad concreta, un objeto que se puede medir, palpar o apreciar en su diseño o en sus timbres por la descripción que hace el texto de ellos, pero no puede transmitir elementos sensitivos o auditivos, como es el temperamento, sino de modo adyacente, alegórico o metafórico.

Sin referencias externas a otros países europeos, este estudio no ignora la complejidad del siglo XVII ni la multiplicidad de sus vías exploratorias ni que "el afán de experimentación en los instrumentos de teclado se había extendido por Europa despertando el interés de teóricos, organeros y constructores" ${ }^{65}$. Lo que sí pone al descubierto, a partir de los textos téoricos de José de Echevarría, sus realizaciones y los de algunos de sus discípulos, es la tercera orientación enarmónica en la construcción

\footnotetext{
${ }^{62}$ A pesar de su importancia, es un tema apenas estudiado; se trata al final del texto en L. Jambou: "Dos categorías de canto litúrgico y su acompañamiento en los siglos modernos: Canto llano y Canto figurado", Inter-American Review, vol. XVII, n. ${ }^{\text {os }} 1$-2, verano 2007, pp. 39-47.

${ }^{63}$ Parece que las últimas reparaciones de teclados de clavicordios con teclas enarmónicas son de los años 1830. G. De Graaf: op. cit., p. 133 habla de "varios instrumentos" existentes hoy y reproduce un ejemplo sin referencia. Por lo que se puede observar es un teclado con teclas partidas prolongadas en el Re sostenido pero no en el La bemol. Nos preocupamos por esta posible existencia en la correspondencia que mantuvimos sobre este punto con Enrique Máximo entre los años 2000 y 2008; la consulta se hizo el 22-XII-2000. No lo observó en ningún instrumento. En años anteriores, en el año 1975 y siguientes tampoco lo observamos nosotros.

${ }^{64}$ Andrés Cea Galán: La cifra hipana..., p. 858, representa el teclado (fig. 1) con teclas partidas.

65 María Sanhuesa Fonseca: El doctor Bartolomeo Giovenardi (ca. 1600-1668). Teórico musical entre Italia y España, Barcelona, CSIC, 2009, p. 78.
} 
de los órganos, que califica el temperamento pretonal de los instrumentos de teclado en general. Una cartografia de sus hombres y de las localizaciones de sus realizaciones aclara que esta se prolonga durante el siglo XVIII y abarca una zona suroriental que espera aún un estudio más amplio y detallado (Figura 1).

Figura 1. Los temperamentos en la Península ibérica a finales del siglo XVII y principios del XVIII (Esquema histórico)

Temperamento protonal:

Temperamento pretonal

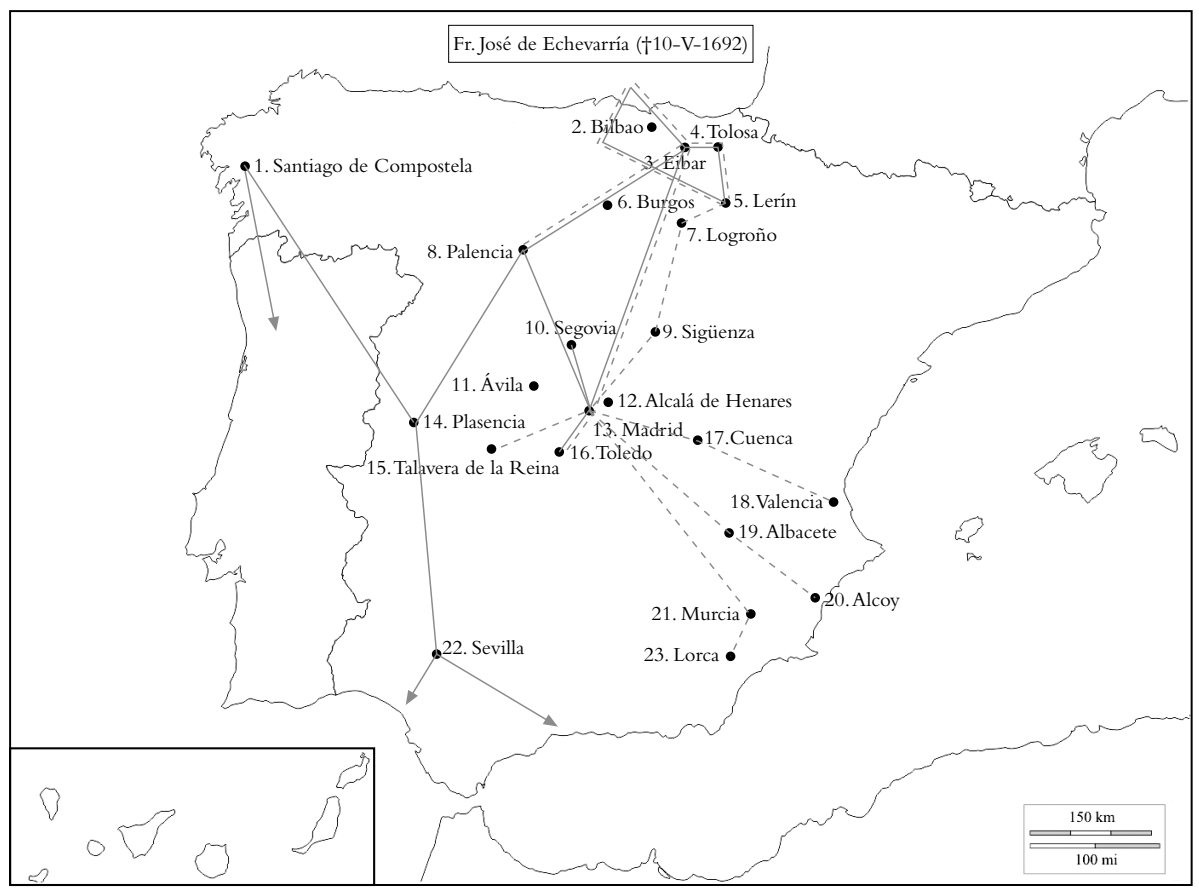

0. José de Echevarría († 10-V-1692).

1. Manuel de la Viña.

2. Ventura de Chavarría (†7-X-1687), Domingo Aguirre $(† 10$ o $11-$ II-1725)

3. José de Echevarría,Ventura Echevarría.

5. Juan de Andueza ( $† 16$ o 17-X-1686), Félix de Yoldi (†12-IV-1695), Domingo Mendoza (†19-IX-1734).

8. José de Echevarría, Domingo Aguirre, Pedro de Liborna Echevarría (†17-II-1725).

9. Domingo Mendoza.

10. Pedro de Liborna Echevarría.

11. Domingo Mendoza.

12. Juan de Andueza, José de Echevarría, Domingo Mendoza, Félix de Yoldi.
13. Juan de Andueza, Domingo Mendoza, Pedro de Liborna Echevarría,Ventura Chavarría, Jorge de Sesma. 14. Domingo Aguirre, Manuel de la Viña (†1724).

15. Juan de Andueza.

16. Domingo Mendoza, Pedro de Liborna Echevarría.

17. Domingo Mendoza, Roque Blasco (†14-VII-1696).

18. Roque Blasco.

19. Miguel Alcarria (†9-IV-1740).

20. Jorge de Sesma (20/22-II-1690), Fulgencio Llop.

21. Fulgencio Llop $(\uparrow 1726)$.

22. Domingo Aguirre.

23. Patricio Campoy $(† 7-\mathrm{X}-1740)$. 


\section{Apéndices}

\section{Documento I}

ACTo. Caja "Órganos".

Obligazion de el Organo $\mathrm{p}^{\text {ra }}$ esta $\mathrm{s}^{\text {ta }}$ yglesia $\mathrm{q}[\mathrm{ue}]$ haze $\mathrm{D}^{\mathrm{n}}$ Pedro echauarria

En la villa de Madrid a ocho dias del mes de junio de mill seiscientos y nobentta y seis años ante mi el ess ${ }^{\text {no }}$ y testigos parezieron Pedro de Liborna y echabarría y doña Cathalina de Alcazar vezinos desta d[ich]a villa de Madrid con lizencia que primero y ante ttodas cossas yo la d[ic] ha Cathalina de Alcazar pido al d[ic]ho Pedro de Liborna y echabarria su [sic] marido para juntam ${ }^{\text {te }}$ con el ottorgar jurar y obligarse a lo que contendra esta escriptura y por el d[ic]ho Pedro de Liborna y echabarría su marido le fue dada y conzedida la $\mathrm{d}[\mathrm{ic}]$ ha lizencia y por la $\mathrm{d}[\mathrm{ic}]$ ha su mujer azeptada de que yo el $\mathrm{ss}^{\text {no }}$ doi fee $=$ y de ella usando junttos y de mancomun a boz de una y cada uno de por si y por el todo ynsolidum renunziando como renunzian las leyes de la mancomunidad de duobus res debendi y la autentica Presente o quieta defide ynsoribus y el rremedio y beneficio de la escursion y dibision epistola del dibo abriano y demas de la man conunidad como en ellas y en cada una de ellas se contiene y debajo de ello $=$ Se obligan con sus Personas y bienes muebles y raizes hauidos y por aber a que el d[ic]ho Pedro de Liborna y echabarría hara fabricara y acabara en toda forma y conforme artte un organo con su caderetta a la partte de adentro Para la santta yglesia de la ciu de Toledo el qual a de azer y ejecutar con los ecoss y contraecos y demas fabrica en el forma sig $^{\text {te }}$

Primeram $^{\text {te }}$ a de llebar quatro fuelles encajonados para que en ningun tiempo los ratones puedan dañarlos los quales an de yr con palancas por no se poder [sic] ruedas y en casso de que se puedan poner las pondra para la mas comodidad de entonar-

Mas a de llebar un flautado de veinte y seis palmos repartido en cinco castillos que an de estar en la fachada de $\mathrm{d}[\mathrm{ic}]$ ho organo enpezando uno de beinte que es guesol.Rud [sic] y los quatro mas bajos a la partte de adentro [dice: adetro] por que an de ser de Madera y los demas, castillos, que ubieren de poner sea de ejecutar conforme a la traza que esta echa y para en poder del $\mathrm{s}^{\text {or }} \mathrm{D}^{\text {or }}$ Don fran ${ }^{\text {co }}$ franco obrero mayor de $\mathrm{d}[\mathrm{ic}]$ ha Santa yglesia-

Ma a de llebar un flautado de treze palmos que esta a de yr dentro y sera de diapason angosto por queda[r] mejor la boz-

Mas un registro de otaba abierta-

Mas un registro de dozena duplicada para dar mucho cuerpo al lleno...

Mas un registro en quinzena-

Un rejistro de diez y nobena duplicado-

Un rejistro de lleno de cinco caños por puntto con sus aumentaçiones en los tiples y bajos y el primer caño en otra quinzena ques caño grande que a de tener el lleno mucho cuerpo-

Mas a de llebar un rejistro de zinbala de cinco caños por Puntto con sus aumentaziones el primer caño en beinte y dosena-

Mas a de llebar una otaba ancha de diapasson-

Mas un [n]asarte en dozena ausado-_

Mas otro nasartte en quinzena-

Mas otro rejistro de seisquialtera- 
Mas otro rejistro de diez y nobena-

Mas otro rejistro de claron que aze un lleno arcornetiado [sic] y sera, otro lleno terzero de cinco caños por puntto

Mas otro rejistro de cornetta magna de siette caños por puntto

Mas otro rejistro de tolozana de cinco caños por punto

Mas otro rejistro de écos, correspondienttes a la cornetta encajonado de yda y de benida con su aconpañamiento en toda la mano-

Mas un rejistro de manos derecha de pinfano [sic]-

[al margen: Rejistros de lengueteria]

Mas a de llebar el d[ic]ho organo un rejistro de trompetas reales de metal-

Mas un medio rejistro de tronpetta magna en unisonus con el flautado veinte y seis-

Mas a de llebar un medio registro de banjonzillo [sic] octaba arriba de la trompetta-

Mas otro medio rejistro de clarin en artillería en la fachada y este a de tener ecos con otro que a de aber encajonado arriba-

Mas a de llebar un rejistro de orlos de ambas manos-

Mas a de llebar quatro tanbores unos en alamire y otros en lasorre para emitar [sic] a los clarines que es de lo mas armoniosso que ay los quales se an de poner, con dos rejistros, en los pies-

Mas a de llebar un teclado a los pies para tañer contras-

Mas a de llebar el d[ich] ho organo unas ruedas de cascabeles y otras de pajaros y gaita y otros adornos q[ue] sirben para días solegnes [sic]-

Asimesmo a de poner en la caja que se yciere para d1ic]ho organos los clarines conforme la platta [= plantta] sin faltar a ella-

Que los mobimientos de todos los rejistros an de ser de yerro por ser mas premanentes [sic] -

[al margen: ] Segdo organo que aze caderetta-

Primeram $^{\text {te }}$ Para el otro organo ques [=que es] la cadereta a de llebar flautado Biolon que abla en unisonus con el flautado prinzipal y teclado del-

Mas a de llebar otaba tapada para dar cuerpo al flautado anttezedentte

Mas a de llebar un lleno de tres caños por puntto-

Mas a de llebar unas tronpettas que se han de poner a ymitazion de las que tiene el realejo que sirbe en la capilla ma ${ }^{\text {or }} \mathrm{de} d[\mathrm{ic}]$ ha santa yglesia en la otaba del Corpus-

Mas a de llebar unos cascabeles de tres caños por puntto

[al margen: esta condiz ${ }^{\text {on }}$ no subsiste [ं?] por $\mathrm{q}^{\text {to }}$ despues se ajusto $\mathrm{q}[\mathrm{ue}]$ ha de hazer todo nuebo, por el mesmo precio q[ue] esta ajustado y consta en esta escrip ${ }^{\text {ra }}$ ]

Es condizion expresa que en la fabrica referida se a de aprobechar por el $\mathrm{d}$ [ic]ho Pedro de echabarria el flautado de veinte y seis que oy tiene el organo biejo anidiendole [sic] quatro caños de Madera y aderezando todo los demas pra que queden perfectos y lo mesmo sea de entender con los caños que pueden serbir del, lleno, y si todo lo demas que no se pueda aprobechar se ha de entregar por pesso al d[ic]ho Pedro de echabarria por quentta del preçio principal del d $[i c]$ ho organo $=Y$ toda la fabrica referida es conforme la traza y disposicion dada por los Padres fr. Martin Garzia fr. Domingo de Aguirre y Don sebastian de uron [sic=Durón] en quinze de diz ${ }^{\text {re }}$ del año pasado de mill y seis cienttos y nobentta y cinco- 
Asimismo es condizion que el d[ic]ho organo a de ttener por detras cinco castillos, dos grandes a cada lado el suyo/ otros dos enzima pequeños y otros ençima de las puertas en medio- y destos an de sonar los catorce caños de los castillos bajos aunque ayan de entrar mas caños $=$ y los otros tres castillos an de ser mudos y de metal fino por cuya fabrica se le a de dar al d[ic]ho Pedro de echabarria duçientos y cinquenta ducados de vellon [al margen: Ojo.] ademas de los cinquenta y seis mill reales del preçio principal de di[ch]o organo cuya cantidad se a de pagar en tres terzios y pagas como yra declarado-

Que el d[ic]ho organo sea de sentar y poner en el sitio destinado donde esta el organo de prima en conformidad de lo dispuesto en la planta-

Que al d[ch]o Pedro de echabarria se le a de dar y pagar por raçon de la [al margen: Precio] fabrica y matteriales de $\mathrm{d}[\mathrm{ch}$ ] ho organo cinquenta y seis mill reales de vellon ademas de los d[ic] hos duçientos y cinquenta ducados por d[ic]ha santa yglesia o por la persona $\mathrm{q}\left[\mathrm{ue}\right.$ ] tubiere obligaz ${ }^{\text {on }}$ a hazerlo en tres pagas [al margen en forma de tabla de sumar: $56000 \mathrm{v} / 2770 / 58750 / 3^{\circ}-190583$ Rs [sic] $11 \mathrm{mrs}$ la metad de todo lo que ynporttare se le a de dar y pagar $\mathrm{q}^{\text {do }}$ conste por certificaz ${ }^{\text {on }}$ de Don Sebastian Duron $\mathrm{u}$ de otra persona o perssonas que su $\mathrm{em}^{\mathrm{ma}}$ nombrare el tener echa la metad de toda la $\mathrm{d}[\mathrm{ic}]$ ha obra $=\mathrm{y}$ la otra tercia $\mathrm{p}^{\text {te }}$ se le a de dar y entregar en la $\mathrm{d}[\mathrm{ic}] \mathrm{ha}$ ciu $^{\mathrm{d}}$ de Toledo quando se enpieze a sentar la d[ic] ha obra y la ultima tercia partte se le a de entregar y satisfazer luego q[ue] conste aya puesto en toda perfeccion el d1ic] ho organo y declaradose por los peritos que su $\mathrm{em}^{\mathrm{ma}}$ nonbrare asi organistas como artifizes de organo aber cumplido sin escussa alguna-

Que la conduccion del organo [al margen: 100 duc $^{\text {os }}$ conduz ${ }^{\text {on }}$ desde esta cortte a la $\mathrm{d}[\mathrm{ic}]$ ha ciudad de Toledo a de correr por quenta de d[ic]ho Pedro de echabarria por cuyos gastos se le an de dar ademas de las cantidades referidas cien ducados de vellon y no ottra cossa alguna-

Que al tiempo de asentarse la d1ic]ha obra a de abisar el d[ic]ho Maestro para que su $\mathrm{em}^{\mathrm{ma}}$ nonbre persona o personas de su satisfaz ${ }^{\text {on }}$ para que bean como ba templando y perfeçionado todas las misturas unas por otras-

Que toda la cañuteria del organo biejo se a de entregar en $\mathrm{d}[\mathrm{ic}]$ ha ciu $^{\mathrm{d}}$ de Toledo al $\mathrm{d}[\mathrm{ic}]$ ho Maestro por su peso quando el lo pidiere y se bea de considerar y cargar al precio $\mathrm{q}[\mathrm{ue}]$ corriere en esta $\mathrm{d}[\mathrm{ic}]$ ha villa y el que ynportare $\mathrm{d}[\mathrm{ic}]$ ho metal se ha de descontar del dinero del segundo plazo-

Es condizion que en el discursso de dos años despues de sentada toda la obra referida del $\mathrm{d}[\mathrm{ic}]$ ho organo se obligan como ba $\mathrm{d}[\mathrm{ic}]$ ha [¿?] a apiar [¿apear?] reconozer y perfizionar el d[ic]ho organo a los tiempos q[ue] conbiniere a sartisfazion de las personas que su $\mathrm{em}^{\mathrm{ma}}$ nombrare y si ubiere algun defecto en $\mathrm{d}[\mathrm{ic}] \mathrm{h}$ organo a de enmendarle por su quenta y costa-

Es condicion que en casso que qualquiera diferencia de las que estan anotadas en la plantta no quepa se le aya de descontar tasando su balor Es condizion que el d[ic]ho Pedro de echabarría a de dar a cabado y en toda perfeccion el d[ic]ho organo en tiempo de dos años q[ue] enpeçaron a correr y contarse desde prim ${ }^{\circ}$ de hen ${ }^{\circ}$ passado deste año de nobentta y seis pero si anttes pudiere sea de atender a que sea como si ubieran cunplido los $\mathrm{d}[\mathrm{ic}]$ hos dos años por lo que toca a la satisfazion de las cantidades referidas-

Es condizion que por partte de la d[ic]ha santa ylesia su obrero mayor o quien le subzediere se le a de dar al d[ic]ho Pedro de echabarría en la d[ic]ha ciu de toledo cassa 
donde bibir y poner la obra por todo el tiempo q[ue] durase el asentarla sin q[ue] por $\mathrm{d}[\mathrm{ic}]$ ha raçon el $\mathrm{d}[\mathrm{ic}]$ ho Maestro pague cossa alguna-

Con las quales condiciones los $\mathrm{d}[\mathrm{ic}]$ hos Pedro de liborna echabarria y da Cathalina de alcazar su mujer debajo de la d[ic] ha mancomunidad se obligan a cunplir y ejecuttar todo lo aqui dispuesto para los plaços referidos sin escussa alguna y en casso de no cumplirlo consientten se les baje descuentte de la cantidad referida mill ducados de vellon que estos an de ser $\mathrm{p}^{\text {ra }}$ la $\mathrm{d}[\mathrm{ic}]$ ha santa yglesia de la $\mathrm{d}[\mathrm{ic}] \mathrm{ha}$ ciu ${ }^{\mathrm{d}}$ de Toledo y en esta conformidad hazen esta obligaz ${ }^{\text {on }}$ con todos las fuerzas nezesarias-

Y estando presentte Don fran ${ }^{c o}$ Anttonio Basauri ajente de $\mathrm{d}[\mathrm{ic}]$ ha obra y fabrica residente en la d[ic]ha villa de Madrid en birtud del poder que tiene del señor $\mathrm{D}^{\text {or }}$ Don fran $^{\text {co }}$ franco canonigo de d[ic] ha santa yglesia de d1ic] ha ciudad de Toledo y su obrero Mayor que para lo que yra declarado q[ue] se le otorgo en ella en quatro de tep ${ }^{\text {te }}[\dot{c}$ ?] mes de junio ante Gabriel Ruiz de Arrieta ess ${ }^{\text {no }}$ publico q[ue] para que conste aqui se ynsiere su tenor y es el sigte__

[al margen: Poder]

En la ciudad de Toledo en quatro dias del mes de junio del año de mill seiscientos y nobenta y seis años ante mi el es ${ }^{\text {no }}$ publico del num ${ }^{\circ}$ y testigos parecio el señor $\mathrm{D}^{\text {or }}$ Don fran ${ }^{\text {co }}$ franco canonigo de la muy santta yglesia desta ciudad Primada de las españas y su obrero mayor y como tal otorgo su poder cunplido el que es nezesario y de derecho se requiere a don Don fran ${ }^{\text {co }}$ Anttonio Basauri ajente de d[ic]ha obra y fabrica en la villa de Madrid expEcial para q[ue] en su nombre pueda ajustar y ajuste con Pedro de echavarría maestro de organero beçino de $\mathrm{d}[\mathrm{ic}]$ ha villa de Madrid un organo que esta resuleto se aga para el serbicio de $d[i c]$ ha santa yglesia y placos en que por ambas parttes esta combenido y que tambien constan del papel que con este poder le seran entregadas otorgando sobre ello las escripturas que fueren nezesarias obligando a esta obra y frabrica a la paga de la cantidad en que asi esta ajustado o se ajustare $\mathrm{d}[\mathrm{ic}]$ ho organo a los placos y con las demas clausulas conbenientes azeptando la obligazion y siguridad que el d1ic]ho Pedro de echabarría diere para el cunplim ${ }^{\text {to }}$ de lo que fuere de su partte q[ue] para todo lo referido cada cossa o partte de ello le da y otorga d[ic] ho poder d[ic]ho Señor obrero mayor con sus yncidencias y dependenzias libres so franca y general administra ${ }^{\text {on }}$ y con la aprobaz ${ }^{\text {on }}$ Ratificazion y Relebazion en derecho nezesaria que al cunplim ${ }^{\text {to }}$ de todo quanto en birttud deste poder yciere obligue y que desde luego $\mathrm{d}[\mathrm{ic}]$ ho $\mathrm{s}^{\text {or }}$ obrero mayor obligo los bienes propios y renttas de $\mathrm{d}[\mathrm{ic}]$ ha obra y fabrica con poderio a las justices y juezes de sus causas conpettentes expecialm ${ }^{\text {te }}$ a las que fuere sometido que desde luego las somete con renunzion de su fuero jusridiscion y domizilio y la ley sit conteneritt de juridiscione onivn yudicum y otras de su fabor con la que proybe la $\mathrm{Gen}^{1} \mathrm{Renunz}^{\text {on }}$ de todas y toda lesion y engaño y menoria de edad y beneficio de la Restituzion yn yntregue y en su nombre como tal obrero mayor lo rezibi por senttenzia passada en cossa juzgada y asi lo otorgo y firmo ante mi el es ${ }^{\text {no }}$ que doy fee le conozco siendo testigos Don Sebastian Montero Manuel Gamarra y Alonso carbonero vezinos de toledo $=\mathrm{D}^{\text {or }}$ Don fran $^{\text {co }}$ franco $=$ Antte mi Gabriel Ruiz de arrieta es $^{\text {no }} \mathrm{pp}^{\mathrm{co}}$

Yo Gabriel Ruiz de arrieta es ${ }^{\text {no }}$ de Su Magd publico del numero desta ynperial ciudad de Toledo y su tierra fui presentte y lo signé en testimonio de verdad= Gabriel Ruiz de arrieta es ${ }^{\text {no }} \mathrm{pp}^{\text {co }}$

[al margen: Prosigue] 
El qual d1ic]ho poder ba ziertto y berdadero y concuerda con su original el qual el d[ic]ho Don francisco Anttonio Basauri dijo tener azeptado y siendo nezesario de nuebo le azepta y en su azeptaz ${ }^{\text {on }}$ dijo le asido leyda y mostrada esta escriptura calidades plaços y condiziones y todo ellos en birtud del d[ic]ho poder lo aprueba y ratifica y obliga a la d[ic]ha Santta Yglesia de la ciudad de toledo y al d[ic]ho Doctor Don fran ${ }^{c o}$ franco como su obrero mayor con sus vienes y renttas a que pagaran al d[ic]ho Pedro de liborna echabarría o a quien su poder ubiere las cantidades contenidas y expresadas en esta escriptura por la caussa y razon q[ue] en ella se rrefiere y precediendo las calidades y condiciones y circunstancias que ban puestas y abiendose cunplido con su tenor y forma el d[1ic]ho Don fran ${ }^{\text {co }}$ Anttonio Bassauri como tal podattario consientte y tiene por bien que el d1ic]ho Pedro de liborna echabarría o quien subzediere en su derecho ejercitte a la d[ic]ha Santa yglesia sus bienes y Renttas y al d[ic]ho s ${ }^{\text {or }}$ obrero mayor que es o fuere de ella por Racon del d[ic]ho oficio y en esta conformidad todas las d[ic]has parttes se obligaron al d[ic]ho Don fran ${ }^{c o}$ $\mathrm{Antt}^{\mathrm{O}}$ con sus bienes Renttas en el poder obligados y el d[ic]ho Pedro de liborna y echabarría y su mujer con sus personas y bienes como ba d[ic] ho y para su ex ${ }^{\text {on }}$ y cumplim $^{\text {to }}$ el d[1ic]ho Don fran ${ }^{\text {co }}$ Anttonio Basauri dio su poder en forma a las justiçias eclesisticas q[ue] deban conozer de la d[ic]ha santta yglesia y de d1ic]ho sor $\mathrm{D}^{\mathrm{r}}$ fran ${ }^{\text {co }}$ franco y especial los sometio a la juridicion del sor Nunçio de su santidad y los d[ic]hos Pedro de liborna y echabarría y su mujer se sometieron al fuero y jurisdiçion de los señores, alcaldes desta corte justicia ordinaria desta villa y a cada uno ynsolidum $\mathrm{p}^{\text {te }}$ que a unos y a otros les conpelan a la guarda y cunplim ${ }^{\text {to }}$ de lo que d[ic]ho es como si fuese sentenzia definitiba de juez compettente passada en cossa juzgada renunziaron leyes de su fabor la Gen en forma- e yo la d[ic]ha Da Cathalina de Alcaraz Renunzio las leyes de los enperadores Justiniano y beleano leyes de toro Madrid y partida y demas del fabor de las mujeres de cuyos efectos yo el es ${ }^{\text {no }}$ doi fee la abise y sabidora dellas las renunzio $=$ y por ser Cassada juro a Dios y a una cruz en forma de derecho a guardar y cunplir lo aqui contenido y no yr contra ello en tiempo alguno alegando $\mathrm{q}[\mathrm{ue}]$ para la hazer y otorgar a sido ynducida ni a atemorizada [sic] por el d[ic] ho su marido ni otra persona alguna por q[ue] confiera la haze de su libre y espontanea boluntad ni se aprobechara de sus bienes dotales ni otros q[ue] la conpetan y si lo yciere no a de ser oyda en juicio ni fuera del y asi lo otorgaron ante mi el $\mathrm{s}^{\text {no }} \mathrm{el} \mathrm{d}[\mathrm{ic}]$ ho dia siendo testigos Lorenzo de ybarguren Juan Suarez y Balthasar Albarez Residentes en esta cortte y lo firmaron los otorg ${ }^{\text {tes }}$ a quienes doy fee conozco $=$ Da Cathalina Alcazar= Don Pedro de liborna echabarría $=$ Don fran ${ }^{\text {co }}$ Anttonio Basauri= Antte mi Thomas de ybarguren-

e yo el $\mathrm{d}[\mathrm{ic}]$ ho Thomas de ybarguren escriu ${ }^{\circ}$ de el Rey nuestro $\mathrm{s}^{\text {or }}$ vez $\mathrm{z}^{\mathrm{o}}$ desta Villa de Madrid Residente en su cortte y prou[i?] $\mathrm{p}$ [resen $]^{\text {te }}$ fui y en fee de elle lo signe y firme en testim ${ }^{\circ}$ de $v[$ erdad] Thomas de ybarguren. 
Documento II. Juan de Castro: Historia del órgano, p. 136r. (Eresbil, Fondo Javier Solaun)

\section{Siglo XVII 66}

Hallándose ya en el siglo XVI el órgano con todos los principales elementos que en la actualidad lo constituyen pudiera dar por terminada esta historia; sin embargo para mayor complemento y para que puedan conocer los juegos o registros que en él se han aumentado y algunas de las innovaciones hechas en su mecanismo añadiré algunas descripciones.

En el siglo XVII, el teclado llegó a extenderse hasta el do de la cuarta octava aguda y también hasta el re de la misma; pero en la primera octava grave faltaban las cuatro notas mencionadas anteriormente [en nota a pie de página viene: A esta clase de organos los llaman de octava corta].

También se hallaban érganos con algunas teclas accidentales dobles como las ya referidas en el siglo anterior al hablar de la pretendida constitución armónica del órgano. Así pues [entre rayas: en] el organo que en la catedral de Ávila se hallaba del lado del Evangelio anteriormente al que ahora existe había la particularidad de tener dos teclas negras en todos los intervalos de segunda mayor que forman las notas $\underline{\text { re }} \underline{\text { mi }}$ y $\underline{\text { sol }}$ la: una de ellas servía para el [p. 137] re sustenido, y la otra para el mi bemol; y las otras,

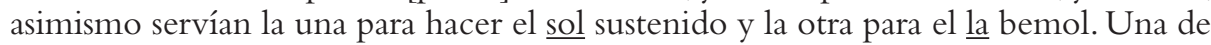
las Dulzainas y una de las trompetas estaban a la espalda y hacían eco al coro. Toda la lenguetería se afinaba por fuera menos una trompeta real, el bajoncillo y la trompeta magna.

Tenia tambien arca de ecos, con un clarin y una corneta [en nota a pie de de página viene: Estos y otros nombres se hallaran esplicados en mi Diccionario general de música antigua y moderna.]: el clarin de campaña se abria y cerraba con un estrivo al pie sin tener que apartar las manos del teclado; y aqui tenemos ya en esto un principio de lo que los organeros extrangeros modernos llaman, combinacion de pedales, y que en este siglo tanto encomian el invento:

Tenia tambien una cadereta cuya maquinaria estaba colocada debajo del organo y no detras.

Tenia este organo cincuenta y siete juegos cuyos nombres y distribucion es como sigue,

\footnotetext{
${ }^{66}$ Este documento es anónimo en el escrito de Juan de Castro. Por lo dicho en él y por los estudios ya realizados por Alfonso de Vicente atribuimos la descripción de sus elementos orgánicos a Domingo Mendoza, que no construye el órgano hasta 1700. Sobre el órgano de la catedral de Âvila, véase Alfonso de Vicente: "Historia de los órganos barrocos de la catedral de Ávila (Primera parte siglo XVIII)", Cuadernos abulenses, n. ${ }^{\circ}$ 15, pp. 149-206, of p. 153 y ss.: el órgano se construye entre 1700 y 1702 por 55000 reales según la escritura cuyo original se desconoce.
} 
Órgano principal

\begin{tabular}{|l|l|}
\hline \multicolumn{1}{|c|}{ Mano izquierda } & \multicolumn{1}{c|}{ Mano derecha } \\
\hline Dos trompetas reales & Dos trompetas reales \\
\hline Dos dulzainas & Dos dulzainas \\
\hline chirimia & Clarin de bajos \\
\hline Bajoncillo & Clarin de campaña \\
\hline Clarin de bajos & Trompeta magna \\
\hline Flautado de 13 & Eco de clarin \\
\hline Octava & Eco de corneta \\
\hline Dos docenas & Flautado de 13 \\
\hline Dos quincenas & Octava \\
\hline Nasardo en $15^{\text {a }}$ & Dos docenas \\
\hline Flautadillo & Dos quincenas \\
\hline Decinovena & Nasardo en $15^{\mathrm{a}}$ \\
\hline lleno & Flautadillo \\
\hline & Decinovena \\
\hline & Lleno \\
\hline & Flauta travesera \\
\hline
\end{tabular}

Cadereta

\begin{tabular}{|l|l|}
\hline \multicolumn{2}{|c|}{ Mano izquierda } \\
\hline Trompeta real & Trompeta real \\
\hline Lleno & Corneta \\
\hline Octava & Lleno \\
\hline Flautadillo & Octava \\
\hline Flautado violon & Flautadillo \\
\hline & Flautado violon \\
\hline
\end{tabular}

Recibido: 11-10-2015

Aceptado: 3-3-2016 